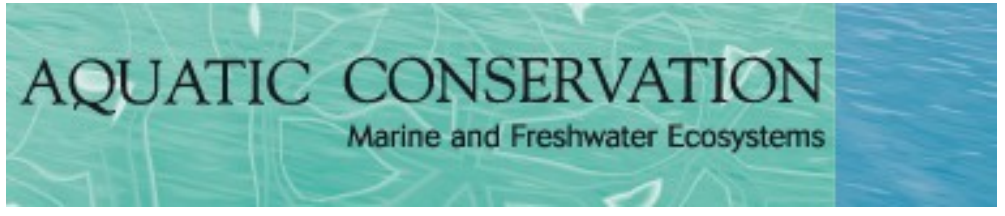

\title{
Assessing the impact of population depletion on mating system in the overexploited Mediterranean red coral
}

\begin{tabular}{|c|c|}
\hline Journal: & Aquatic Conservation: Marine and Freshwater Ecosystems \\
\hline Manuscript ID & AQC-19-0220.R1 \\
\hline Wiley - Manuscript type: & Research Article \\
\hline $\begin{array}{r}\text { Date Submitted by the } \\
\text { Author: }\end{array}$ & $\mathrm{n} / \mathrm{a}$ \\
\hline Complete List of Authors: & $\begin{array}{l}\text { Ledoux, Jean-Baptiste ; Interdisciplinary Centre of Marine and } \\
\text { Environmental Research (CIIMAR) in Porto, Portugal, } \\
\text { Frias, Silvia; Institut de Ciencies del Mar } \\
\text { Motero-Serra, Ignasi; Universitat de Barcelona } \\
\text { Antunes, Agostinho; Interdisciplinary Centre of Marine and } \\
\text { Environmental Research (CIIMAR) in Porto, Portugal } \\
\text { Casado-Bueno, Clara; Universitat de Barcelona } \\
\text { Civit, Sergi; Universitat de Barcelona } \\
\text { Lopez-Sendino, Paula; Institut de Ciencies del Mar } \\
\text { Linares, Cristina; University of Barcelona, Evolutionary Biology, Ecology } \\
\text { and Environmental Sciences } \\
\text { Garrabou, Joaquim; Institut de Ciencies del Mar }\end{array}$ \\
\hline $\begin{array}{l}\text { Broad habitat type } \\
\text { (mandatory) select 1-2: }\end{array}$ & $\begin{array}{l}\text { coastal < Broad habitat type, reef }<\text { Broad habitat type, subtidal }< \\
\text { Broad habitat type }\end{array}$ \\
\hline $\begin{array}{l}\text { General theme or application } \\
\text { (mandatory) select } 1-2 \text { : }\end{array}$ & $\begin{array}{l}\text { biodiversity }<\text { General theme or application, genetics }<\text { General theme } \\
\text { or application, reproduction }<\text { General theme or application }\end{array}$ \\
\hline $\begin{array}{l}\text { Broad taxonomic group or } \\
\text { category (mandatory, if } \\
\text { relevant to paper) select } 1-2 \text { : }\end{array}$ & $\begin{array}{l}\text { benthos }<\text { Broad taxonomic group or category, invertebrates }<\text { Broad } \\
\text { taxonomic group or category }\end{array}$ \\
\hline $\begin{array}{l}\text { Impact category (mandatory, } \\
\text { if relevant to paper) select } 1- \\
2:\end{array}$ & climate change $<$ Impact category, fishing $<$ Impact category \\
\hline
\end{tabular}

\section{SCHOLARONE ${ }^{m}$ \\ Manuscripts}




\section{Assessing the impact of population decline on mating system in the} overexploited Mediterranean red coral

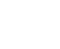

\section{Jean-Baptiste Ledoux ${ }^{1,2}$, Silvia Frias-Vidal ${ }^{1}$, Ignasi Montero-Serra ${ }^{3}$, Agostinho Antunes ${ }^{2}$,}

\section{Clara Casado Bueno ${ }^{1}$, Sergi Civit ${ }^{4}$, Paula Lopez-Sendino ${ }^{1}$, Cristina Linares ${ }^{3}$, Joaquim}

\section{Garrabou ${ }^{1,5}$}

(
(1)

1 Institut de Ciències del Mar, CSIC, Passeig Marítim de la Barceloneta 37-49, 08003 Barcelona, Spain

2 CIIMAR/CIMAR, Centro Interdisciplinar de Investigação Marinha e Ambiental, Universidade do Porto, Porto, 4050-123, Portugal

3 Departament de Biologia Evolutiva, Ecologia i Ciències Ambientals, Universitat de Barcelona, Av. Diagonal 643, 08028 Barcelona, Spain.

4 Departament d’Estadística, Facultat de Biologia, Universitat de Barcelona, Avinguda Diagonal 643, 08028 Barcelona, Spain

5 Aix-Marseille University, Mediterranean Institute of Oceanography (MIO), 13288, Marseille, Cedex 9; Université de Toulon, 83957,

CNRS/IRD, France

Corresponding author: Jean-Baptiste Ledoux

Telephone: +34932306046

Fax: +34934111438

E-mail: jbaptiste.ledoux@gmail.com

Running title: Population decline, mating pattern and genetic drift in the red coral

Keywords: population decline; overfishing; mating system; inbreeding; genetic drift;

\section{Mediterranean octocoral}




\section{ABSTRACT}

1. Understanding the interactions among demographic parameters, mating system and population dynamics is key to predict the response of populations to global change. The Mediterranean red coral is a precious octocoral suffering from population decline due to overfishing and warming-driven mass mortality events.

2. While the demographic consequences of these two pressures are well characterized, little is known regarding their impact on population dynamics and evolution of red coral populations. The main objective of this study was to fill this gap focusing more particularly on mating pattern and genetic drift.

3. Combining sibship and progeny arrays analyses, a genetical characterization of the red coral mating system was conducted. In addition, a synchronic approach was developed comparing mating patterns in two populations with contrasted demographic patterns: a pristine-like population and a declining population.

4. The results show that polyandry is likely the norm in the red coral. The similar patterns of genetic diversity between adults and larvae combined to the lack of differential reproductive success among putative fathers did not support significant sweepstakes effects during larval production. While instantaneous biparental inbreeding was detected, no long-term inbreeding was observed even in the declining population. Mating patterns and effective population sizes in the two populations were not statistically different. Nevertheless, a trend towards a slightly higher inbreeding and a lower number of breeders was observed in the declining population.

5. Accordingly, we hypothesized that an increase in male gamete dispersal may buffer the increase of genetic drift expected in the declining population. This feedback between demographic decline and reproductive pattern may potentially takes part in the longterm persistence of red coral populations. However, the negative trend reported in the 
declining population unambiguously supports the need to maintain high densities of reproductive colonies to promote the functioning of red coral populations. 


\section{INTRODUCTION}

The characterization of the interactions among demographic parameters, population dynamics and evolution of natural populations is key to define effective conservation policies (Ferrière, Dieckmann \& Couvet 2004). In this context, the eco-evolutionary consequences of population decline induced by habitat fragmentation or overexploitation received particular attention in the past decades (e.g. Duminil et al. 2016; Dunlop, Eikeset \& Stenseth 2015). Population decline is expected to cause the loss of genetic diversity due to an increase of genetic drift and inbreeding (Charlesworth \& Willis 2009), which should, in turn, increase extinction risk (Spielman et al. 2004) and decrease adaptive potential (Frankham, Bradshaw \& Brook 2014). The magnitude of the decrease of genetic diversity and the increase of drift and inbreeding are directly linked to the variation of effective population size $\left(N_{e}\right)$ (Serbezov, Jorde, Bernatchez, Olsen \& Vøllestad 2012; Wright 1931). $N_{e}$ is a fundamental parameter for conservation biologists (Frankham 1995), which links population dynamics and underlying evolutionary processes (Hare et al. 2011). Indeed, $N_{e}$ is related to different ecological drivers (e.g. population demographic parameters, life-history traits and mating systems; see Hedrick 2005; Nunney 1993; Waples 2006) and it gives insights into the evolutionary potential of a population (Hare et al. 2011). A drawback is that $N_{e}$ is notoriously difficult to estimate in wild populations (Gilbert \& Whitlock 2015) and the relationship between $N_{e}$ and its ecological drivers is still a matter of debate (Karl 2008; Pearse \& Anderson 2009).

In the marine realm, the majority of invertebrates are characterized by bentho-pelagic life cycles with a dispersive larval phase and a sessile adult phase. The reproduction usually involves longlived, late-maturing and highly fecund individuals following a promiscuous mating strategy, in which any males mate with any females and vice versa (Karl 2008). As a by-product of promiscuity, multiple paternity (i.e. siring of a female clutch by more than one male) is likely to occur (e.g. Lasker, Gutiérrez-Rodríguez, Bala, Hannes \& Bilewitch 2008; Mokthar-Jamai et 
104 al. 2013; Warner et al. 2016). Marine invertebrates are also usually characterized by reduced $105 N_{e}$ values compared to their high census population size $\left(N_{c}\right)$ (Hauser \& Carvalho 2008; Hedrick 106 2005). This reduction was explained by a differential reproductive success among individuals, 107 the "sweepstakes reproductive success" hypothesis (Hedgecock 1994). Genetic imprints of 108 sweepstake effects include a decrease in genetic diversity and an increase of linkage 109 disequilibrium and relatedness from adults to recruits, which should result in a significant 110 genetic differentiation between cohorts (Hedgecock \& Pudovkin 2011). While multi-paternity 111 and sweepstakes effect were demonstrated in different species (e.g. Christie, Johnson, Stallings 112 \& Hixon 2010; Selkoe, Gaines, Caselle \& Warner 2006), their ubiquity in the marine realm still 113 remains to be characterized (Hedgecock \& Pudovkin 2011). Moreover, the impact of population

114 decline on those particular mating patterns and the consequences for the evolutionary potential 115 in marine invertebrates are still poorly understood (but see Plough, Moran \& Marko 2014; Xue, 116 Zhang \& Liu 2016).

117 Here, the main objective was to gain insights into the putative feedbacks between mating 118 patterns and demographic decline focusing on the Mediterranean red coral, Corallium rubrum. 119 Distributed in the western Mediterranean and neighbouring Atlantic Ocean (Zibrowius, 120 Monteiro-Marques \& Grasshoff 1984), this precious octocoral with slow population dynamics, 121 shows unambiguous signs of population decline due to overfishing for its use in jewelry and 122 warming-induced mass mortality events (Garrabou et al. 2017; Montero-Serra, Linares, Doak, 123 Ledoux \& Garrabou 2018). The red coral is a gonochoric brooder with internal fertilization, 124 balanced sex-ratio, annual reproductive cycle and late sexual maturity (i.e. 10 years of age) 125 (Torrents \& Garrabou 2011; Torrents, Garrabou, Marschal, \& Harmelin 2005; Tsounis, Rossi, 126 Aranguren, Gili, \& Arntz 2006). Significant isolation by distance was demonstrated among 127 colonies geo-referenced over half a square metre confirming a limited effective dispersal 128 (Aurelle \& Ledoux 2013; Costantini, Fauvelot, \& Abbiati 2007a,b; Ledoux et al. 2010a) and 
129 suggesting that reproduction units are restricted in space and composed of genetically related 130 individuals (Ledoux et al. 2010b). The subtle temporal genetic structure demonstrated among 131 adults and juveniles implied a low level of genetic drift at this spatial scale (Ledoux et al. 132 2010b). A lack of temporal genetic structure was reported among recruits and juveniles coming 133 from two reproductive events in the same population (Costantini, Rugiu, Cerrano, \& Abbiati 134 2018). While these studies shed new light on the reproduction of the red coral, a formal genetic 135 characterization of the mating pattern is still essentially lacking. Moreover, the putative impacts 136 of population decline on reproductive pattern remain to be tested.

137 Focused for the very first time on the larval phase in the red coral, this study aims to: i) 138 genetically characterize the mating system with particular emphasis on multipaternity and

139 inbreeding; ii) test for the sweepstakes reproductive success hypothesis by characterizing 140 patterns of genetic diversity, relationships and temporal genetic structure among adults and 141 larvae; and iii) estimate the strength of genetic drift based on different estimators of the number 142 of breeders $\left(N_{b}\right)$. To achieve these aims, a synchronic approach (i.e. the analyses of variations 143 among contrasted populations at a given time) was developed by comparing the results of 144 progeny arrays and sibship analyses in two red coral populations with highly contrasting 145 demographic structure: a pristine-like (Garrabou et al. 2017) and a declining population 146 (Linares et al. 2012).

148 MATERIALS AND METHODS

149 Sampling

150 Corallium rubrum colonies were sampled by scuba-diving at two sites with similar habitat 151 features: Grotte Harmelin in Corsica $\left(42.38^{\circ} \mathrm{N}, 8.54^{\circ} \mathrm{E}\right.$, France; HAR) and Pedra de Déu in 152 Medes Islands $\left(42.0461^{\circ} \mathrm{N}, 3.22477^{\circ} \mathrm{E}\right.$; Spain; DEU) (Figure 1). HAR is one of the last 153 pristine-like shallow populations of red coral. It is characterized by the highest biomass of large- 
154 sized colonies ( $>10 \mathrm{~cm}$ in height) reported to date in the Mediterranean Sea with the co155 existence of colonies of different sizes resulting in high density (201 colonies x m $\mathrm{m}^{-2}$ ) (Garrabou 156 et al. 2017). In contrast DEU, while situated in the "Parc natural del Montgri, les Illes Medes i

157 el Baix Ter", shows signs of population decline with a shift in population size structure with

158 the absence of large-size colonies, and lower biomass and density $\left(49.4\right.$ colonies $\times \mathrm{m}^{-2}$;

159 Garrabou unpublished data; Linares et al. 2012). The sampling was conducted in June 2013 at 160 the beginning of the annual reproduction period (Torrents \& Garrabou 2011; Tsounis et al. 161 2006; Santangelo et al. 2003). Small fragments (1 to $2 \mathrm{~cm})$ from adults with high reproductive 162 potential (height $>5 \mathrm{~cm}$; see Torrents, Garrabou, Marschal, \& Harmelin, 2005) were randomly 163 hand-collected over three square metres in the two populations $(\mathrm{N}=30$ and $\mathrm{N}=33$ in DEU and

164 HAR, respectively). The fragments were preserved in $95 \%$ ethanol and stored at $-80^{\circ} \mathrm{C}$ until 165 sexing and DNA extraction.

166 Sexing was conducted by dissecting polyps under a binocular microscope. When a female 167 colony was identified, 10 additional polyps were dissected and all the larvae were collected, 168 preserved in $95 \%$ ethanol and stored at $-80^{\circ} \mathrm{C}$ until DNA extraction.

DNA extraction, microsatellite genotyping, quality control and microsatellite characteristics DNA extractions and genotyping of eight microsatellites previously developed in this species (Ledoux et al. 2010a) are detailed in Appendix A. MICRO-CHECKER 2.2.3 (Van Oosterhout 173 et al. 2004) was used to test scoring errors. Because null alleles and genotyping errors can bias 174 parentage analyses (Dakin \& Avise 2004), we aimed to minimize their impact on the following 175 analysis. First, all the individuals with more than two null genotypes (i.e. no amplification) 176 were discarded. Then, a preliminary parentage analysis in COLONY 2.0.6.1 (Jones \& Wang 177 2010) was conducted. Knowing the true maternal sibships between females and larvae, the 178 objective of this analyses was to test whether the information contained in the genotypes was 
179 sufficiently robust to reconstruct these relationships without specifying the maternal sibships.

180 Only the larvae that were assigned with a probability equal to 1 to their true mother were 181 retained. The final dataset comprised 204 samples coming from two populations (DEU and

182 HAR) and assigned to two different stage-classes (adults [AD] and larvae [LAR]). In DEU, we 183 analyzed 67 larvae (DEU-LAR) from eight mothers and 30 adults (DEU-AD; 10 males and 20

184 females including the eight mothers). In HAR, we analyzed 74 larvae (HAR-LAR) from 11 185 mothers and 33 adults (HAR-AD; 19 males and 14 females including the 11 mothers) (Table $1861)$.

188 Genetic diversity analyses, long-term inbreeding and temporal genetic structure between 189 adults and larvae

190 Frequencies of null alleles were estimated for each locus within each stage-class (i.e. adults and 191 larvae) in FREENA (Chapuis \& Estoup 2007). Tests for linkage equilibrium in each stage-class 192 were conducted in GENETIX 4.05 (Belkhir et al. 2004) using 1000 permutations. The observed 193 heterozygosity $\left(H_{o}\right)$ and gene diversity $\left(H_{e}\right.$; Nei 1973) were computed for each stage-class in 194 GENEPOP 4.1.4 (Rousset 2008). ADZE (Szpiech et al. 2008) was used to compute the allelic 195 richness $\left(A r_{g}\right)$ using the rarefaction method (Petit et al. 1998) with $g$, the minimum number of 196 genes at a locus in a population, equals to 56. The values of $H_{e}$ and $A r_{(56)}$ were compared 197 between stage-classes in each population using Wilcoxon signed rank tests.

198 Because null alleles bias the estimation of $F_{I S}$, INEST (Chybicki \& Burczyk 2009) was used 199 under the Population Inbreeding Model to compute the $F_{I N E S T}$, an unbiased estimate of 200 inbreeding coefficient. A first full model accounting for null alleles, inbreeding and genotyping 201 failures was run for 200,000 iterations, a thinning of 100 and 50,000 burn-in. To test whether 202 inbreeding was a significant component of the model, this model was compared with a model 
203 without inbreeding based on the Deviance Information Criterion (DIC). The model with the 204 lower DIC was retained.

205 Temporal genetic differentiation was estimated based on pairwise $F_{S T}$ among adults and larvae 206 within each population using $\theta$, the Weir \& Cockerham's (1984) estimator of $F_{S T}$. Genotypic 207 differentiation was tested using an exact test with default parameters in GENEPOP.

\section{Mating system analysis}

Instantaneous biparental inbreeding and correlated paternity

211 Based on the maternal progeny arrays, the multilocus outcrossing rate $\left(t_{m}\right)$ and the single 212 outcrossing rate $\left(t_{s}\right)$ were computed for each population (HAR: 11 families; DEU: 8 families) 213 using the maximum likelihood method and Newton-Raphson iterations as implemented MLTR 214 v.3.2 (Ritland 2002). A conservative approach was adopted excluding Mic25 and Mic27, which 215 showed the highest level of null alleles and genotyping errors, respectively. The difference 216 between $t_{m}-t_{s}$ was used to estimate the level of instantaneous biparental inbreeding (mating 217 among close relatives) in each population. In addition, the correlated paternity $\left(r_{(p)}\right)$ defined as 218 the proportion of full sibs within maternal progeny arrays was estimated for each population. 219 The standard deviation and 95\% confidence intervals ( $95 \%$ CI) of each parameter were 220 estimated using a bootstrap procedure by resampling families 1000 times. These $95 \%$ CI were 221 used to test whether the estimated values were different from 0 and for comparison among 222 populations.

\section{Characterization of the pattern of relationships}

224 The maximum-likelihood method implemented in COLONY 2.0.6.1 (Jones \& Wang 2009) was 225 used to reconstruct the pattern of relationships among larvae and to assign paternity in each 226 population accounting for genotyping errors (Wang 2004). The levels of allelic dropout were 227 set to the frequencies of null alleles computed for each locus (see Wang 2004). For all loci, the 
228 other type of genotyping errors was set to 0.01 , an upward estimation of error rates based on 229 the re-genotyping procedure (not shown). Known maternal sibs, the excluded maternity and the 230 excluded maternal sibs were defined. Three runs with different seed numbers were conducted 231 considering females and males as polygamous and using the Full-Likelihood method with very 232 high and very long likelihood precision and length of run, respectively. The robustness of the 233 results was tested using a reduced dataset of six microsatellites excluding Mic25 and Mic27. 234 Because patterns of relationships were consistent and robust among runs, the results obtained 235 for one run only are shown.

\section{Sweepstakes reproductive success hypothesis}

$238 \quad$ Test of reproductive skew among putative fathers

239 In case of sweepstake effects, differential reproductive success among individuals is expected 240 (i.e. reproductive skew). The occurrence of differential reproductive success among the males 241 inferred with COLONY in each population was tested using the Nonacs binomial skew index $242 B$ implemented in SKEW CALCULATOR (Nonacs 2000, 2003). $B$ ranges from -1 to +2 . 243 Random mating is observed for $B=0$; negative values suggest that reproduction is more evenly 244 distributed than expected while positive values correspond to a skew greater than expected 245 suggesting differential reproductive success among individuals. The one-tailed p-value 246 associated with $B$ in each site was computed with 5000 simulations. The $95 \%$ confidence 247 interval of $B$ in each site was estimated.

$248 \quad$ Comparison of relatedness estimators among stage-classes

249 Sweepstake effects also induced an increase of genetic relatedness from reproductive adults to 250 their descendants. The levels of relatedness for each stage-class in each population were 251 computed using Lynch-Li moment-estimator (Li, Weeks \& Chakravarti 1993; Lynch 1988) in 
252 COANCESTRY (Wang 2011). The significance of the differences of the average relatedness 253 between adults and larvae in each population was tested using a bootstraps procedure (1000). 254

\section{5}

Estimation of effective population size $\left(\mathrm{N}_{\odot}\right)$ and relative impact of genetic drift

According to the challenges linked to estimation of effective population size $\left(N_{e}\right)$ in long-lived 257 and iteroparous species (Waples 2010; Wang 2016), such as the red coral, different estimators 258 of $N_{e}$ were computed (Hare et al. 2011). These computations, based on larvae coming from a 259 single reproductive event, results in an estimation of effective number of breeders $\left(N_{b}\right)$ instead 260 of a "true" $N_{e}$. Empirical works suggested similar results between the two parameters (e.g. 261 Beedee 2009; Duong, Scribner, Forsythe, Crossman, \& Baker 2013).

262 Four estimators of $N_{b}$ were computed: i) the sibship assignment method (Wang 2009); ii) the 263 standard linkage disequilibrium method (Hill 1981) with Waples' (2006) correction under the 264 random-mating model, excluding rare alleles with frequencies of less than 0.02 and using a 265 jackknife procedure to estimate confidence intervals (Waples \& Do 2008, 2010); iii) the method 266 based on molecular coancestry (Nomura et al. 2008). We also computed iv) moment-based F267 statistics estimator (Jorde \& Ryman 2007; Waples 1989) considering a sampling plan I (see 268 Waples 2005 for details) and that the adults and the larvae in each population were separated 269 by one generation. The last three estimators were computed using NeEstimator v.2 (Do et al. 270 2014). Following Waples \& Do (2010) and Riquet et al. (2016), an unweighted harmonic mean 271 of $N_{b}$ in each population was computed to obtain an overall estimate of effective population 272 size.

274 RESULTS

275 Microsatellite characteristics, stage-class genetic diversity, long-term inbreeding and 276 temporal genetic structure 
277 No evidence of scoring errors due to stuttering or large allele dropout was found. In the two 278 populations, all loci were polymorphic (p-value $<0.01)$. The frequency of null alleles $(r)$ was 279 between 0.09 for HAR-AD and HAR-LAR and 0.12 for DEU-AD and DEU-LAR (mean over 280 populations $\pm \mathrm{SE}=0.1 \pm 0.02)$. Observed heterozygosity values $\left(H_{o}\right)$ were between 0.49 for 281 DEU-LAR and 0.53 for HAR-AD (mean over populations $\pm \mathrm{SE}=0.51 \pm 0.01$ ). The gene 282 diversity $\left(H_{e}\right)$ ranged between 0.65 (HAR-LAR) and 0.72 (DEU-AD) (mean over populations $283 \pm \mathrm{SE}=0.68 \pm 0.03)$. Regarding $A r_{(56)}$, the highest and lowest values were observed for DEU$284 \mathrm{AD}(11.1)$ and HAR-LAR (9) (mean $A r_{(56)}$ over samples $\left.\pm \mathrm{SE}=9.9 \pm 1.03\right)$. None of the 285 Wilcoxon signed ranked tests conducted to compare $H_{e}$ and $A r_{(56)}$ among adults and larvae in 286 each population were significant after FDR correction for multiple tests (Table 1). $F_{I N E S T}$ 287 estimators were low but higher in adults compared to larvae (0.04 vs 0.02 in DEU and 0.03 vs. 2880.01 in HAR). In all the cases, the model without inbreeding showed the lowest DIC suggesting 289 a lack of inbreeding (results not shown).

290 The two temporal $F_{S T}$ s were low (0.002 for DEU-AD vs. DEU-LAR and 0.005 for HAR-AD 291 vs. HAR-LAR) but significant (p-values $<0.05)$.

293 Mating system analyses

Instantaneous biparental inbreeding and correlated paternity

295 The multilocus outcrossing rates $\left(t_{m}\right)$ were close to 1 in both populations as expected in strictly 296 outcrossing species. The single outcrossing rate $\left(t_{s}\right)$ was 0.78 for DEU and 0.74 for HAR 297 resulting in a higher signal of biparental inbreeding $\left(t_{m}-t_{s}\right)$ in $\operatorname{DEU}(0.21 ; 95 \% \mathrm{CI}=0.13-0.45)$ 298 than in $\operatorname{HAR}(0.17 ; 95 \% \mathrm{CI}=0.07-0.26)$. Based on the $95 \% \mathrm{CIs}$, the estimates of biparental 299 inbreeding were significantly different from 0 in the two populations but the estimates were not 300 significantly different between the two populations. Estimates of correlated paternity were 0.23 
$301(95 \% \mathrm{CI}=0.09-0.46)$ for DEU and 0.12 for HAR $(95 \% \mathrm{CI}=-0.03-0.25)$. The two estimates 302 were not significantly different based on their 95\% CI (Table 2).

$303 \quad$ Pattern of relationships

304 Considering only relationships with a probability $>0.8$, in DEU, six full-sib dyads and 246 half305 sib dyads over the 2211 putative relationships were retained, corresponding to $0.27 \%$ and 11.12 $306 \%$, respectively. The total number of fathers was 32. In HAR, two full-sib dyads and 235 half307 sib dyads over the 2701 putative relationships were observed, corresponding to $0.07 \%$ and 8.7 $308 \%$, respectively. The total number of fathers was 43 . Evidence of multiple paternity was found 309 in all the families from the two populations. The number of fathers for each family in DEU 310 ranged from 6 to 10, with a mean value of $7.5 \pm 1.5$ fathers. In HAR, the number of fathers for 311 each family varied from 2 to 10 , with a mean value of $6.5 \pm 2.4$ fathers. The putative fathers 312 were involved in multiple mating events producing 1 to 5 larvae, with a mean value of $2.1 \pm$ 3131.1 in DEU and a mean value of $1.9 \pm 1$ in HAR (Figure 2). 314

\section{Sweepstakes reproductive success hypothesis}

$316 \quad$ Reproductive skew among putative fathers

317 Although the number of larvae per putative father ranged from 1 to 5, the skew observed among 318 males was not significantly different from random expectations in the two populations $(B=-$ $3190.0057, \mathrm{p}$-value $=0.973$ in $\mathrm{DEU} ; \mathrm{B}=-0.008 \mathrm{p}$-value $=1$ in HAR). This suggests a similar 320 contribution of the different fathers to the pool of larvae.

$321 \quad$ Comparison of relatedness estimators among stage-classes

322 Mean estimates of relatedness based on the Lynch-Li moment-estimator ranged from $-8.84 * 10^{-2}$ 323 in DEU-AD to $7.65^{*} 10^{-2}$ in HAR-LAR. The differences of mean relatedness between adults 324 and larvae were significant in the two populations (Table 3). 
327 Based on the sibship assignment method, $N_{b}$ was 29 (95\%CI: 18-49) for DEU and 39 (95\%CI:

328 25-61) for HAR. The linkage disequilibrium and the molecular coalescent estimates of $N_{b}$ were

32938.3 (95 \%CI: 30-50) and 4.7 (95 \%CI: 1.9-8.7) in DEU and 35.9 (95\%CI: 29.1-45) and infinity

330 in HAR, respectively. The estimates of $N_{b}$ obtained with the temporal method were 25.5 (95

331 \%CI: 17.4 - 35) in DEU and 34 (95 \%CI: 22.6 - 47.7) in HAR. The resulting harmonic means

332 of $N_{b}$ were 12.8 for DEU and 48.2 for HAR (Table 4).

333

\section{DISCUSSION}

335 The impact of demographic decline on population dynamics and evolution is a central concern

336 for conservation biologists. This study is the first genetic characterization of the mating system

337 of an internal brooding octocoral. In spite of a lack of statistically significant differences in the 338 mating patterns of the two red coral populations, a higher biparental inbreeding and correlated 339 paternity combined with a lower number of breeders were reported in the declining population.

340 While the results presented here may potentially be affected by the occurrence of null alleles,

341 it is noteworthy that the dataset was filtered to decrease their impact (e.g. only mother/larvae

342 pairs with assignment probability $=1$ were retained). A broad set of complementary analyses 343 relying on different statistical methods was also used and showed concordant results (i.e. 344 sibship reconstruction $v s$. progeny array analyses, four different $\mathrm{Nb}$ estimators). Moreover, 345 simulations considering different levels of genotyping errors demonstrated the robustness of 346 the sibship reconstruction method implemented in COLONY (Wang 2004). The implications 347 of these results for the basic ecological knowledge of the red coral and for its evolution in the 348 context of population decline is discussed below.

350 Does multipaternity buffer long-term inbreeding? 
351 Multipaternity is likely the norm in the red coral. Indeed, the 19 progeny arrays analysed were 352 sired by more than one male as supported both by the sibship analyses in COLONY and by the 353 correlation of paternity estimated in MLTR. Polyandry is expected in promiscuous mating 354 species and was previously demonstrated in one red coral population based on kinship analyses 355 among juveniles and adults (Ledoux et al. 2010b). The estimated mean number of larvae per 356 father inferred in COLONY over the two populations studied here $(1.88+/-0.9$ larvae / father $)$ 357 is in the same order as those previously reported in the same species $(2.3+/-0.8$ offspring / 358 parent; Ledoux et al. 2010b) and in another tropical octocoral Antillogorgia elisabethae (1.42 359 +/- 0.7 larvae / father; Lasker, Gutiérrez-Rodríguez, Bala, Hannes, \& Bilewitch 2008) and 360 slightly lower than in the Mediterranean Paramuricea clavata $(6.6+/-4.7$ larvae / father; 361 Mokhtar-Jamaï et al. 2013). Variations in the level of multiple paternity among species are 362 usual in marine invertebrates (e.g. Brante, Fernandez, \& Viard 2011; Warner et al. 2016). While 363 polyandry is a widespread strategy among organisms from sessile marine invertebrates to social 364 mammals and including wind-pollinated plant and tree species (Simmons 2005), its evolution 365 remains a controversial issue (Yasui et al. 2016). Focusing on sessile marine species in which 366 polyandry is passive (i.e. females passively receive the gamete from different males), the 367 adaptive value is questioned. Multiple mating may simply be correlated to the selective pressure 368 increasing fertilization success when multiple individuals are present (Brante, Fernandez, \& 369 Viard 2011; Johnson \& Yund 2007). Alternatively, the adaptive hypothesis lies on indirect 370 genetic benefits for the females. Polyandry may increase offspring survival enhancing in turn 371 female reproductive fitness by increasing the genetic diversity, and the viability or the 372 competiveness of the offspring through advantageous male genes (see Yasui \& Garcia373 Gonzales 2016; Zeh \& Zeh 2000 for reviews).

374 While it is notoriously challenging to test for indirect genetic effects (Yasui \& Garcia-Gonzales 375 2016) and acknowledging the complexity of the interactions between mating system and 
376 inbreeding (Frankham 1995), a decrease of inbreeding was also proposed as one of the indirect 377 genetic benefits of multipaternity (Zeh \& Zeh 2000). Here, the inbreeding varied in function of 378 the temporal scale. The progeny array approach supports significant level of instantaneous 379 biparental inbreeding (i.e. crossing between related mates). This result is in accordance with 380 the view of red coral populations as mosaics of spatially restricted breeding units $(<$ one square 381 metre) composed by relatives (Ledoux et al. 2010b). In contrast, when considering the 382 multilocus inbreeding coefficients unbiased by null alleles $\left(F_{\text {INEST }}\right)$, which estimate the 383 combined effect of inbreeding depression (i.e. the fitness decrease observed in related 384 individuals) and biparental inbreeding over several generations, inbreeding was not statistically 385 supported. This absence of long-term inbreeding may appear surprising considering the high 386 and significant $F_{I S}$ values reported in previous studies (e. g. Ledoux et al. 2010a). Nevertheless, 387 these $F_{I S}$ values were likely biased by null alleles and Wahlund effect (Ledoux et al. 2010a). 388 Further analyses such as estimations of inbreeding coefficients on well-defined cohorts (from 389 larvae to recruits, juveniles and adults) and reproduction experiments in aquaria should be 390 envisaged to formally test a putative buffering effect of multipaternity on inbreeding in the red 391 coral.

\section{Soft sweepstakes effect and low genetic drift in the red coral.}

394 Interestingly, larvae production does not seem to be impacted by strong sweepstakes effects in 395 this species. None of the genetic diversity parameters tested were significantly different 396 between larvae and adults in the two populations. No linkage disequilibrium was reported in 397 the larvae although it is expected when a small number of individuals produced the next 398 generation. Moreover, while a significant increase of genetic relatedness was reported from 399 adults to larvae, the genetic differentiation between the two stage-classes in each population 400 was only marginally significant. The high polymorphism of the microsatellites used here may 
401 partially explain these results (Hedgecock \& Pudovkin 2011). Nevertheless, the absence of 402 sweepstake effect is also supported by the lack of reproductive skews among the fathers inferred 403 with COLONY. Sweepstakes effect is expected in promiscuous sessile marine invertebrates 404 with larval phase (Hedegecock \& Pudovkin 2011) but the lack of sweepstake observed here is 405 also supported by the null to low temporal differentiation previously reported among juveniles 406 and adults (Ledoux et al. 2010b) or recruits and juveniles (Costantini, Rugiu, Cerrano, \& 407 Abbiati 2018). This can be related to red coral life-history traits and in particular, to the 408 occurrence of mating among individuals from overlapping generations, which may buffer 409 temporal changes of allelic frequencies (Riquet, Le Cam, Fonteneau, \& Viard 2016). 410 Comparing genetic characteristics among well-defined cohorts rather than stage-classes is 411 needed to assess this hypothesis.

412 The impact of a promiscuous mating system on $N_{e}$ and genetic drift has been previously debated 413 (Karl 2008; Pearse \& Anderson 2009). In species with a generation time greater than 10 years 414 such as the red coral, multipaternity should only marginally impact $N_{e}$ (Lotterhos 2011). While 415 estimates of $N_{e}$ must be considered cautiously and considering that similarity between $N_{b}$ and $416 N_{e}$ was assumed here, the results support moderate to high numbers of breeders in the two 417 populations. These values are concordant with the high $N_{e}$ previously reported over a similar 418 spatial area in the long-lived and polyandrous octocoral P. clavata (Mokhtar-Jamaï et al. 2013). 419 However, they contrast with the general trend in marine species in which $N_{e}$ was shown to be 420 orders of magnitude lower than the census population size $\left(N_{c}\right)$ and genetic drift is usually 421 stronger than expected (Hare et al. 2011; Hauser \& Carvalho 2008). In accordance with the lack 422 of sweepstake effect previously discussed, the estimations of $N_{b}$ suggest genetic drift to be 423 limited at the fine spatial and temporal scales under survey. This result supports recent studies 424 questioning the ubiquity of low $N_{e} \mathrm{~s}$ in marine species (Hare et al. 2011; Riquet, Le Cam, 425 Fonteneau, \& Viard 2016). 


\section{Does population decline impact red coral mating system and effective population size?}

428 The site "Grotte Harmelin" (HAR) is considered as one of the last pristine-like shallow 429 population of red coral offering the opportunity to characterize the baseline population 430 dynamics in this species (Garrabou et al. 2017). Contrasting the results obtained in this 431 population with the results obtained in a declining population (DEU) provides the first insights 432 into the consequences of demographic decline on mating system and effective population size 433 in the red coral.

434 None of the parameters (correlated paternity, biparental inbreeding and number of breeders) 435 estimated to compare the mating patterns between the two populations were significantly 436 different. This result contrasts with the positive correlation between population density and 437 mating pattern reported in copulating marine invertebrates (e.g., barnacles (Plough, Moran, \& 438 Marko 2014); marine snails (Xue, Zhang, \& Liu 2016)). In these species, the probability of 439 mate encounter increases with population density. The lack of differences among the two 440 populations is concordant with what was found between low and high-density populations in a 441 sperm-cast ascidian (Johnson \& Yund 2007). In sperm-cast species such as the red coral, the 442 spermatozoa may cross greater distances in the water column in low density populations 443 buffering the influence of density on mate interactions (e.g. Duminil et al. 2016). Nevertheless, 444 in spite of this lack of statistically significant differences between the two populations, all the 445 analyses suggest some negative consequences of demographic decline. A trend toward higher 446 biparental inbreeding and correlated paternity combined with a lower number of breeders is 447 observed in the declining compared to the pristine-like population. Accordingly, we 448 hypothesized the expected increase in genetic drift, due the lower mate density in DEU 449 compared to HAR, to be balanced to some point by an increase of male gamete flow. While the 450 hypothesized buffering effect of male gamete flow remains to be formally tested in the red 
451 coral, it is likely subtle and limited as supported by the negative trend observed in the declining 452 population. The characterization of spatial genetic structures in populations with contrasted 453 demographic patterns and the inference of related demographic parameters (e.g. effective 454 dispersal) is required to go further in this hypothesis and to improve our understanding of the 455 feedbacks between demographic decline and mating patterns in the red coral. 456

457 Overall, this study suggests the occurrence of subtle feedbacks between demographic and 458 reproductive patterns in red coral populations. In complement to other processes (e.g. re-growth 459 of damaged colonies; see Montero-Serra et al. 2015), these feedbacks may partially explain the 460 long-term persistence of red coral populations in spite of the millennial fishing pressure. They 461 are likely to provide a borrowed time (sensu Hughes, Linares, Dakos, van de Leemput, \& van 462 Nes 2013) for the management and conservation of this threatened species. Nevertheless, the 463 negative trend reported in the declining population unambiguously supports the maintenance 464 of high density of reproductive colonies, and accordingly the diminution of direct 465 anthropogenic pressures (e.g. fishing), as a prerequisite to maintain functional red coral 466 populations. 


\section{5}

476

477

478

479

480

481

482

483

484

\section{ACKNOWLEDGEMENTS}

485

Funding was provided by the Fundação para a Ciência e a Tecnologia (FCT)

486

(UID/Multi/04423/2019), the Spanish MINECO (CGL2012-32194), the TOTAL Foundation PERFECT project, the MIMOSA project funded by the foundation Prince Albert II de

488

Monaco, and the European Union's Horizon 2020 research and innovation program under

489

490 grant agreement $\mathrm{N}^{\circ} 689518$ (MERCES). This output reflects only the author's view and the European Union cannot be held responsible for any use that may be made of the information contained therein

JBL was supported by a postdoctoral grant (SFRH/BPD/74400/2010) from Fundação para a Ciência e a Tecnologia (FCT), CL by a Ramon y Cajal (RyC-2011-08135), IMS by a FPI grant (BES-2013-066150) and SC by research project SGR 622 (GRBIO) from the Departament d' Economia i Coneixement de la Generalitat de Catalunya and (PGC2018095931-B-I00) MINECO (Spain). Genotyping was performed at the Genome Transcriptome Facility of Bordeaux (grants from the Conseil Régional d'Aquitaine n²0030304002FA and 20040305003FA, from the European Union FEDER n²003227 and from Investissements

500 d'Avenir ANR-10-EQPX-16-01). 


\section{REFERENCES}

506 Aurelle, D., \& Ledoux, J.-B. (2013). Interplay between isolation by distance and genetic clusters in the red coral Corallium rubrum: Insights from simulated and empirical data. Conservation Genetics, 14(3), 705-716.

Ayre, DJ., \& Miller, K. (2006). Random mating in the brooding coral Acropora palifera. Marine Ecology Progress Series, 148 (8), 876-888.

Beebee, T.J.C. (2009). A comparison of single-sample effective size estimators using empirical toad (Bufo calamita) population data: genetic compensation and population size-genetic diversity correlations. Molecular Ecology, 18(23), 4790-4797.

Brante, A., Fernandez, M., \& Viard, F. (2011). Microsatellite evidence for sperm storage and extreme multiple paternity in the protrandous gastropod Crepidula coquimbensis. Journal of Experimental Marine Biology and Ecology, (396), 83-88.

Bruckner, A. (2009). Rate and extent of decline in Corallium (pink and red coral) populations: existing data meet the requirements for a CITES Appendix II listing. Marine Ecology Progress Series, 397, 319-332.

Charlesworth, B. \& Willis, J.H. (2009). Fundamental concepts in genetics: effective population size and patterns of molecular evolution and variation. Nature Reviews. Genetics, 10(3), 195-205.

Christie, M.R., Johnson, D.W., Stallings, C.D., and Hixon, M.A. (2010). Self-recruitment and sweepstakes reproduction amid extensive gene flow in a coral-reef fish. Molecular Ecology, 19(5), 1042-1057.

Costantini, F., Fauvelot, C., \& Abbiati, M. (2007a). Fine-scale genetic structuring in Corallium rubrum: Evidence of inbreeding and limited effective larval dispersal. Marine Ecology Progress Series, 340, 109-119.

Costantini, F., Fauvelot, C., \& Abbiati, M. (2007b). Genetic structuring of the temperate gorgonian coral (Corallium rubrum) across the western Mediterranean Sea revealed by microsatellites and nuclear sequences. Molecular Ecology, 16(24), 5168-5182.

Costantini, F., Rugiu, L., Cerrano, C., \& Abbiati, M. (2018). Living upside down: patterns of red coral settlement in a cave. PeerJ 6:e4649 https://doi.org/10.7717/peerj.4649.

Do, C., Waples, R.S., Peel, D., Macbeth, G.M., Tillett, B.J., \& Ovenden, J.R. (2014). NeEstimator $v 2$ : re-implementation of software for the estimation of contemporary effective population size $\left(N_{e}\right)$ from genetic data. Molecular Ecology Resources, 14(1), 209-214.

Duminil, J., Daïnou, K., Kaviriri, D.K., Gillet, P., Loo, J., Doucet, J.L., \& Hardy, O.J. (2016). Relationships between population density, fine-scale genetic structure, mating system and pollen dispersal in a timber tree from African rainforests. Heredity, 116(3), 295-303.

Dunlop, E.S., Eikeset, A.M., \& Stenseth, N.C. (2015). From genes to populations: how fisheries-induced evolution alters stock productivity. Ecological Applications, 25(7), 1860-1868.

Duong, T.Y., Scribner, K.T., Forsythe, P.S., Crossman, J., \& Baker, E. (2013). Interannual variation in effective number of breeders and estimation of effective population size in long-lived iteroparous lake sturgeon (Acipenser fulvescens). Molecular Ecology, 22(5), 1282-1294.

Ferrière R., Dieckmann U., \& Couvet D. (2004). Evolutionary Conservation Biology. (Camb Univ Press). Cambridge.

Frankham, R. (1995). Conservation Genetics. Annual Review of Genetics, 29(1), 305-327.

Frankham, R., Bradshaw, C.J.A., \& Brook, B.W. (2014). Genetics in conservation management: Revised recommendations for the 50/500 rules, Red List criteria and population viability analyses. Biological Conservation, 170, 56-63. 
554 Garrabou, J., Coma, R., Bensoussan, N., Bally, M., Chevaldonné, P., Cigliano, M., ... Cerrano, C. (2009). Mass mortality in Northwestern Mediterranean rocky benthic communities: Effects of the 2003 heat wave. Global Change Biology, 15, 1090-1103.

Garrabou, J., Sala, E., Linares, C., Ledoux, J.-B., Montero-Serra, I., Dominici, J.-M., ... Harmelin, J.-G. (2017). Re-shifting the ecological baseline for the overexploited Mediterranean red coral. Scientific Reports, 7, 42404.

Gilbert, K.J., \& Whitlock, M.C. (2015). Evaluating methods for estimating local effective population size with and without migration. Evolution, 69(8), 2154-2166.

Hare, MP., Nunney, L., Schwartz, MK., Ruzzante, DE., Burford, M., Waples, RS., ... Palstra, F. (2011). Understanding and estimating effective population size for practical application in marine species management. Conservation Biology, 25(3), 438-449.

Hauser, L., \& Carvalho, G.R. (2008). Paradigm shifts in marine fisheries genetics: ugly hypotheses slain by beautiful facts. Fish and Fisheries, 9(4), 333-362.

Hedgecock, D. (1994). Does variance in reproductive success limit effective population size of marine organisms? Genetics and evolution of aquatic organisms A.Beaumont Ed. (Chapman and Hall). London .

Hedgecock, D., \& Pudovkin, A.I. (2011). Sweepstakes reproductive success in highly fecund marine fish and shellfish: a review and commentary. Bulletin of Marine Science, 87(4), 971-1002.

Hedrick, P. (2005). Large variance in reproductive success and the $N_{e} / N$ ratio. Evolution; International Journal of Organic Evolution, 59(7), 1596-1599.

Hill, WG. (1981). Estimation of effective population size from data on linkage disequilibrium. Genetical Research, 38(3), 209.

Hughes, T.P., Linares, C., Dakos, V., van de Leemput, I.A., \& van Nes, E.H. (2013). Living dangerously on borrowed time during slow, unrecognized regime shifts. Trends in Ecology and Evolution, 28(3), 149-155.

Johnson, SL., \& Yund, P.O. (2007). Variation in multiple paternity in natural populations of a free-spawning marine invertebrate. Molecular Ecology, 16(15), 3253-3262.

Jones, O.R., \& Wang, J. (2010). Molecular marker-based pedigrees for animal conservation biologists. Animal Conservation, 13(1), 26-34.

Jorde, P.E., \& Ryman, N. (2007). Unbiased estimator for genetic drift and effective population size. Genetics, 177(2), 927-935.

Karl, S.A. (2008). The effect of multiple paternity on the genetically effective size of a population. Molecular Ecology, 17(18), 3973-3977.

Lasker, H., Gutiérrez-Rodríguez, C., Bala, K., Hannes, A., \& Bilewitch, J. (2008). Male reproductive success during spawning events of the octocoral Pseudopterogorgia elisabethae. Marine Ecology Progress Series, 367, 153-161.

Ledoux, J.-B., Garrabou, J., Bianchimani, O., Drap, P., Féral, J.-P., \& Aurelle, D. (2010). Fine-scale genetic structure and inferences on population biology in the threatened Mediterranean red coral, Corallium rubrum. Molecular Ecology, 19(19), 4204-4216.

Ledoux, J.-B., Mokhtar-Jamaï, K., Roby, C., Féral, J.-P., Garrabou, J., \& Aurelle, D. (2010). Genetic survey of shallow populations of the Mediterranean red coral [Corallium rubrum (Linnaeus, 1758)]: New insights into evolutionary processes shaping nuclear diversity and implications for conservation. Molecular Ecology, 19(4), 675-690.

Li, C., Weeks, D., \& Chakravarti, A. (1993). Similarity of DNA fingerprints due to chance and relatedness. Human Heredity, 43, 45-52.

Linares, C., Garrabou, J., Hereu, B., Diaz, D., Marschal, C., Sala, E., \& Zabala, M. (2012). Assessing the effectiveness of marine reserves on unsustainably harvested long-lived sessile invertebrates. Conservation Biology, 26(1), 88-96.

Lotterhos, KE. (2011). The context-dependent effect of multiple paternity onf effective 
604 population size. Evolution, 65(6), 1693-1706.

605 Lynch, M. (1988). Estimation of relatedness by DNA fingerprinting. Molecular Biology and Evolution, 5(5), 584-599.

McCauley, D.J., Pinsky, M.L., Palumbi, S.R., Estes, JA., Joyce, FH., \& Warner, RR. (2015). Marine defaunation: animal loss in the global ocean. Science, 347(6219), 1255641.

Miller, KJ., \& Ayre, DJ. (2008). Population structure is not a simple function of reproductive mode and larval type: insights from tropical corals. The Journal of Animal Ecology, 77(4), 713-724.

Mokhtar-Jamai, K., Coma, R., Wang, J., Zuberer, F., Feral, J.-P., \& Aurelle, D. (2013). Role of evolutionary and ecological factors in the reproductive success and the spatial genetic structure of the temperate gorgonian Paramuricea clavata. Ecology and Evolution, 3(6), 1765-1779.

Montero-Serra, I., Linares, C., Doak, DF., Ledoux, J.-B., \& Garrabou, J. (2018). Strong linkages between depth, longevity and demographic stability across marine sessile species. Proceedings of the Royal Society serie B, 285(1873), 1765-1777.

Nomura, T. (2008). Estimation of effective number of breeders from molecular coancestry of single cohort sample. Evolutionary Applications, 1(3), 462-74.

Nonacs, P. (2000). Measuring and using skew in the study of social behavior and evolution. American Naturalist, 156, 577-589.

Nonacs, P. (2003). Measuring the reliability of skew indices: is there one best index? Animal Behaviour, 65, 615-627.

Nunney, L. (1993). The Influence of mating system and overlapping generations on effective population size. Evolution, 47(5), 1329-1341.

Pearse, D.E., \& Anderson, E.C. (2009). Multiple paternity increases effective population size. Molecular Ecology, 18(15), 3124-3127.

Pinsky, M.L., \& Palumbi, S.R. (2014). Meta-analysis reveals lower genetic diversity in overfished populations. Molecular Ecology, 23, 29-39.

Plough, LV, Moran, A., \& Marko, P. (2014). Density drives polyandry and relatedness influences paternal success in the Pacific gooseneck barnacle, Pollicipes elegans. BMC Evolutionary Biology, 14(1), 81.

Riquet, F., Le Cam, S., Fonteneau, E., \& Viard, F. (2016). Moderate genetic drift is driven by extreme recruitment events in the invasive mollusk Crepidula fornicata. Heredity, $117(1), 42-50$.

Ritland, K. (2002). Extensions of models for the estimation of mating systems using $\mathrm{n}$ independent loci. Heredity, 88(4), 221-228.

Rousset, F. (2008). genepop'007: a complete re-implementation of the genepop software for Windows and Linux. Molecular Ecology Resources, 8(1), 103-106.

Santangelo, G., Carletti, E., Maggi, E. \& Bramanti L. (2003). Reproduction and population sexual structure of the overexploited Mediterranean red coral Corallium rubrum. Marine Ecology Progress Series, 248, 99-108.

Selkoe, K.A., Gaines, S.D., Caselle, J.E., \& Warner, R.R. (2006). Current shifts and kin aggregation explain genetic patchiness in fish recruits. Ecology, 87(12), 3082-3094.

Serbezov, D., Jorde, P.E., Bernatchez, L., Olsen, E.M., \& Vøllestad, L.A. (2012). Life history and demographic determinants of effective/census size ratios as exemplified by brown trout (Salmo trutta). Evolutionary Applications, 5(6), 607-618.

Simmons, LW. (2005). The Evolution of polyandry: Sperm competition, sperm selection, and offspring viability. Annual Review of Ecology, Evolution, and Systematics, 36(1), 125146.

Spielman, D., Brook, BW., \& Frankham, R. (2004). Most species are not driven to extinction before genetic factors impact them. Proceedings of the National Academy of Sciences, 
660

661

662

663

664

665

666

667

668

669

670

671

672

673

674

675

676

677

678

679

680

681

682

683

684

685

686

687

688

689

690

691

692

693

694

695

696

697

698

699

700

701

101(42), 15261-15264.

Torrents, O., \& Garrabou, J. (2011). Fecundity of red coral Corallium rubrum (L.) populations inhabiting in contrasting environmental conditions in the NW Mediterranean. Marine Biology, 158(5), 1019-1028.

Torrents, O., Garrabou, J., Marschal, C., \& Harmelin, J.-G. (2005). Age and size at first reproduction in the commercially exploited red coral Corallium rubrum (L.) in the Marseilles area (France, NW Mediterranean). Biological Conservation, 121, 391-397.

Tsounis G., Rossi S., Aranguren M., Gili J-M., \& Arntz W. (2006) Effects of spatial variability and colony size on the reproductive output and gonadal development cycle of the Mediterranean red coral (Corallium rubrum L.). Marine Biology, 148, 513-527.

Wang, J. (2004) Sibship reconstruction from genetic data with typing errors. Genetics, 166(4), 1963-1979.

Wang, J. (2011). Coancestry: a program for simulating, estimating and analysing relatedness and inbreeding coefficients. Molecular Ecology Resources, 11(1), 141-145.

Wang, J. (2016). A comparison of single-sample estimators of effective population sizes from genetic marker data. Molecular Ecology, 25(19), 4692-4711.

Waples, R.S. (1989). A generalized approach for estimating effective population size from temporal changes in allele frequency. Genetics, 121(2), 379-391.

Waples, R.S. (2005). Genetic estimates of contemporary effective population size: to what time periods do the estimates apply? Molecular Ecology, 14(11), 3335-3352.

Waples, R.S. (2006). A bias correction for estimates of effective population size based on linkage disequilibrium at unlinked gene loci. Conservation Genetics, 7(2), 167-184.

Waples, R.S. (2010). Spatial-temporal stratifications in natural populations and how they affect understanding and estimation of effective population size. Molecular Ecology Resources, 10(5), 785-796.

Waples, R.S., \& Do, C. (2008). ldne : a program for estimating effective population size from data on linkage disequilibrium. Molecular Ecology Resources, 8(4), 753-756.

Waples, R.S., \& Do, C. (2010). Linkage disequilibrium estimates of contemporary $N_{e}$ using highly variable genetic markers: a largely untapped resource for applied conservation and evolution. Evolutionary Applications, 3(3), 244-262.

Warner, R., Kaidonis, M., Dun, O., Rogers, K., Shi, Y., Nguyen, TTX., \& Woodroffe, CD. (2016). Opportunities and challenges for mangrove carbon sequestration in the Mekong River Delta in Vietnam. Sustainability Science, 11(4), 661-677.

Weir, BS., \& Cockerham, CC. (1984). Estimating F-Statistics for the Analysis of Population Structure. Evolution, 38(6), 1358.

Wright, S. (1931). Evolution in mendelian populations. Genetics, 16(2), 97-159.

Xue, D.-X., Zhang, T., \& Liu, J.-X. (2016). Influences of population density on polyandry and patterns of sperm usage in the marine gastropod Rapana venosa. Scientific Reports, 6(1), 23461.

Yasui, Y., \& Garcia-Gonzalez, F. (2016). Bet-hedging as a mechanism for the evolution of polyandry, revisited. Evolution, 70(2), 385-397.

Zeh, DW., \& Zeh, JA. (2000). Reproductive mode and speciation: the viviparity-driven conflict hypothesis. BioEssays, 22(10), 938-946.

Zibrowius, H., Monteiro-Marques, V., \& Grasshoff, M. (1984). La répartition du Corallium rubrum dans l'Atlantique (Cnidaria: Anthozoa: Gorgonaria). Téthys, 11, 163-170. 
702

703

704

706

707

708

709

710

711

712

713

714

715

716

717

718

719

720

721

722

Authors' contributions:

JBL, CL and JG designed the study. CL, CCB and IMS performed sexing and larvae collection. JBL, PLS, SF and CCB performed laboratory work. JBL, SF and SC analyzed the data. JBL and SF wrote the manuscript with input from all authors. All authors approved the manuscript.

\section{Data accessibility:}

Microsatellite genotypes will be made available on Dryad.

\section{Supporting information:}

Additional information may be found in the online version of the article:

Appendix A: DNA extraction and microsatellite genotyping

723

724

725

726

727

728

729

730

731

Conflict of interest: No conflict of interest to declare. 
733 Table 1: Genetic diversity of each stage-class in each site (DEU and HAR). $N$ : number of

734 individuals; $r$ : frequency of null alleles; $H_{o}$ : observed heterozygosity; $H_{e}$ : gene diversity;

$735 \operatorname{Ar}_{(56)}$ : rarefied allelic richness considering a minimum of 56 genes at a locus in a population;

$736 \quad F_{\text {INEST: }}$ estimate of inbreeding coefficient unbiased by null alleles.

737

738

\begin{tabular}{|c|c|c|c|c|c|c|c|}
\hline & $N$ & $r$ & $H_{o}$ & $H_{e}$ & $A r$ & $A r_{(56)}$ & $F_{I N E S T}$ \\
\hline DEU-AD & 30 & 0.12 & 0.52 & 0.72 & 11.25 & 11.1 & 0.04 \\
\hline DEU-LAR & 67 & 0.12 & 0.49 & 0.69 & 11 & 9.1 & 0.02 \\
\hline HAR-AD & 33 & 0.09 & 0.53 & 0.66 & 10.62 & 10.3 & 0.03 \\
\hline HAR-LAR & 74 & 0.09 & 0.52 & 0.65 & 11.62 & 9 & 0.01 \\
\hline
\end{tabular}




\section{0}

741 Table 2: Mating system characteristics for each site. $t_{m}$ : multilocus outcrossing rate; $t_{s}$ : single

742 outcrossing rate; $t_{m}-t_{s}$ : level of biparental inbreeding; $r_{(p)}$ : correlated paternity. The $95 \%$

743 confidence intervals $(95 \% \mathrm{CI})$ of each parameter was estimated by resampling families 1000 744 times.

745

746

\begin{tabular}{|l|l|c|c|c|}
\cline { 2 - 5 } \multicolumn{1}{c|}{} & \multicolumn{1}{|c|}{$t_{m}[95 \% \mathrm{CI}]$} & $t_{s}[95 \% \mathrm{CI}]$ & $t_{m}-t_{s}[95 \% \mathrm{CI}]$ & \multicolumn{1}{c|}{$r_{(p)}[95 \% \mathrm{CI}]$} \\
\hline $\mathrm{DEU}$ & $0.99[0.95 ; 1.2]$ & $0.78[0.64 ; 0.89]$ & $0.21[0.13 ; 0.45]$ & $0.23[0.09 ; 0.46]$ \\
\hline $\mathrm{HAR}$ & $0.94[0.86 ; 1]$ & $0.77[0.67 ; 0.88]$ & $0.17[0.07 ; 0.26]$ & $0.12[-0.03 ; 0.25]$ \\
\hline
\end{tabular}

747

748

749

750

751

752

753

754

755

756

757

758

759

760

761 
762 Table 3: Estimates of relatedness for each stage-class in each population using the $L L$ : Lynch-

763 Li moment-estimator of relatedness. Observed value corresponds to the difference between

764 adults and larvae in each population. The significance of the differences among the two stage-

765 classes was tested using on 1000 bootstraps. Significant differences are shown in bold.

766

767

\begin{tabular}{|c|c|c|}
\hline & Lynch-Li & $\begin{array}{c}\text { Observed Value and } 95 \% \\
\text { CI }\end{array}$ \\
\hline $\begin{array}{l}\text { DEU- } \\
\text { AD }\end{array}$ & $-8.84 \times 10^{-2}$ & \\
\hline $\begin{array}{l}\text { DEU- } \\
\text { LAR }\end{array}$ & $2.31 \times 10^{-3}$ & $\begin{array}{c}9 \times 10^{-2} \\
{\left[-2.5 \times 10^{-2} ; 2.51 \times 10^{-2}\right]}\end{array}$ \\
\hline $\begin{array}{l}\text { HAR- } \\
\text { AD }\end{array}$ & $5.28 \times 10^{-2}$ & \\
\hline $\begin{array}{l}\text { HAR- } \\
\text { LAR }\end{array}$ & $7.65 \times 10^{-2}$ & $\begin{array}{c}2.37 \times 10^{-2} \\
{\left[-2.55 \times 10^{-2} ; 1.95 \times 10^{-2}\right]}\end{array}$ \\
\hline
\end{tabular}

768

769

770

771

772

773

774

775

776

777

778

779 


\section{0}

781

782 Table 4: Effective population size and $95 \%$ confidence interval (between brackets) computed

783 for each site using: i) the sibship assignment method; ii) the standard linkage disequilibrium

784 method; iii) the method based on molecular coancestry; and iv) the moment based F-statistics 785 methods.

786

787

788

\begin{tabular}{|c|c|c|c|c|c|}
\cline { 2 - 6 } \multicolumn{1}{c|}{} & $\begin{array}{c}\text { Sibship } \\
\text { assignment } \\
\text { method } \\
\text { (Wang } \\
2009)\end{array}$ & $\begin{array}{c}\text { Standard linkage } \\
\text { disequilibrium } \\
\text { method } \\
\text { (Hill 1981) }\end{array}$ & $\begin{array}{c}\text { Molecular } \\
\text { coancestry } \\
\text { method } \\
\text { (Nomura et al. } \\
\text { 2008) }\end{array}$ & $\begin{array}{c}\text { Moment-based F- } \\
\text { statistics } \\
\text { estimator } \\
\text { (Waples 1989; } \\
\text { Jorde \& Ryman } \\
2007)\end{array}$ & $\begin{array}{c}\text { Unweighted } \\
\text { harmonic mean }\end{array}$ \\
\hline DEU & $29[18-49]$ & $38.3[30-50]$ & $4.7[1.9-8.7]$ & $25.5[17.4-35]$ & 12.8 \\
\hline HAR & $39[25-61]$ & $35.9[29.1-45]$ & infinity & $34[22.6-47.7]$ & 48.2 \\
\hline
\end{tabular}

789

790

791

792

793

794

795

796

797

798 


\section{FIGURE LEGENDS:}

800

801 Figure 1: Location of the two study sites: Pedra de Deu (DEU) in the Medes Islands within

802 the Parc Natural del Montgrí, illes Medes i Baix Ter (Spain) and Grotte Harmelin (HAR)

803 within the Réserve Naturelle de Scandola in Corsica (France). Pictures A and B show

804 populations DEU and HAR, respectively. The same quadrat $(20 \times 20 \mathrm{~cm})$ is used in the two 805 pictures.

806

807 Figure 2: Kinship structure among larvae from each population (DEU and HAR) 808 reconstructed based on their multilocus genotypes using COLONY. L/M: number of larvae per 809 mother; L/F: number of larvae per putative father. Grey and blue squares correspond to one and

810 two larvae, respectively, for the mother-putative father pair considered. * pair of larvae inferred 811 as fullsib with a probability higher than 0.8 . 
5 Jean-Baptiste Ledoux ${ }^{1,2}$, Silvia Frias-Vidal ${ }^{1}$, Ignasi Montero-Serra ${ }^{3}$, Agostinho Antunes ${ }^{2}$,

6 Clara Casado Bueno ${ }^{1}$, Sergi Civit ${ }^{4}$, Paula Lopez-Sendino ${ }^{1}$, Cristina Linares ${ }^{3}$, Joaquim

\section{$7 \quad$ Garrabou $^{1,5}$}

8

9

10 1 12 13 14 15 16

17 Corresponding author: Jean-Baptiste Ledoux

18 Telephone: +34932306046

19 Fax: +34934111438

20 E-mail: jbaptiste.ledoux@gmail.com overexploited Mediterranean red coral

1 Institut de Ciències del Mar, CSIC, Passeig Marítim de la Barceloneta 37-49, 08003 Barcelona, Spain

2 CIIMAR/CIMAR, Centro Interdisciplinar de Investigação Marinha e Ambiental, Universidade do Porto, Porto, 4050-123, Portugal

3 Departament de Biologia Evolutiva, Ecologia i Ciències Ambientals, Universitat de Barcelona, Av. Diagonal 643, 08028 Barcelona, Spain.

4 Departament d'Estadística, Facultat de Biologia, Universitat de Barcelona, Avinguda Diagonal 643, 08028 Barcelona, Spain

5 Aix-Marseille University, Mediterranean Institute of Oceanography (MIO), 13288, Marseille, Cedex 9; Université de Toulon, 83957, CNRS/IRD, France

\section{Assessing the impact of population decline on mating system in the}

22 Running title: Population decline, mating pattern and genetic drift in the red coral

Keywords: population decline; overfishing; mating system; inbreeding; genetic drift;

Mediterranean octocoral 


\section{ABSTRACT}

1. Understanding the interactions among demographic parameters, mating system and population dynamics is a critical step key to predict the response of populations to global change. The Mediterranean red coral is a precious octocoral suffering from population decline due to overfishing and warming-driven mass mortality events.

2. While the demographic consequences of these two pressures are well characterized, little is known regarding their impact on population dynamics and evolution of red coral populations. Our The main objective of this study was to fill this gap focusing more particularly on mating pattern and genetic drift.

3. Combining sibship and progeny arrays analyses, we a genetically eharacterized characterization of the mating system of the red coral was conducted. and-In addition, developed-a synchronic approach was developed comparinging mating patterns in two populations with contrasted demographic patterns: a pristine-like population and a declining population.

\section{3.}

4. The results show that we demonstrated thatppolyandry is likely the norm in this speciese

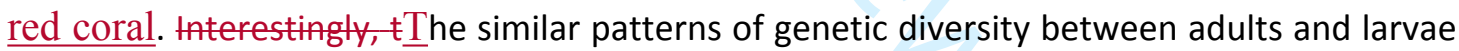
combined to the lack of differential reproductive success among putative fathers did not support significant sweepstakes effects during larval production. While detected instantaneous biparental inbreeding was detected, no long-term inbreeding was observed even in the declining population. Mating patterns and effective population sizes in the two populations were not statistically different. Nevertheless, a trend towards a slightly higher inbreeding and a lower number of breeders was observed in the declining population.

4. Overall, no differences in mating patterns and similar estimates of effective population size were observed despite the contrasted demographic patterns of the two populations. 
5. Acordingly, Accordingly, we hypothesized that an increase in male gamete dispersal may buffer the increase of genetic drift expected in the declining population. This $\underline{\text { feedback between demographic decline and reproductive pattern may potentially takes }}$ part in the long-term persistence of red coral populations. However, the negative trend reported in the declining population unambiguously supports the need to maintain high densities of reproductive colonies to promote the functioning of red coral populations. 60 we hypothesized that higher gamete dispersal may buffer to some point the potential 61 increase of genetic drift expected during population decline. Red coral populations may 62 thus be resilient to some levels of decline explaining potentially their long term persistence 63 in spite of the millennial fishing pressure. 64 65 66 67 68 69 70 71 72 


\section{9}

80

81

82

83

84

$85 \quad 5$.

86 INTRODUCTION

87 The characterization of the interactions among demographic parameters, population dynamics

88 and evolution of natural populations is key to define effective conservation policies (Ferrière,

89 Dieckmann, \& Couvet, 2004). In this context, the eco-evolutionary consequences of population

90 decline induced by habitat fragmentation or overexploitation received particular attention in the

91 past decades (e.g. Duminil et al. 2016; Dunlop, Eikeset, \& Stenseth, 2015; Duminil et al. 2016).

92 Population decline is expected to cause the loss of genetic diversity due to an increase of genetic

93 drift and inbreeding (Charlesworth \& Willis 2009), which should, in turn, increase extinction

94 risk (Spielman et al. 2004) and decrease adaptive potential (Frankham, Bradshaw, \& Brook, 95 2014). The magnitude of the decrease of genetic diversity and the increase of drift and 96 inbreeding are directly linked to the variation of effective population size $\left(N_{e}\right)$ (Serbezov, Jorde, 97 Bernatchez, Olsen, \& Vøllestad, 2012; Wright 1931). $N_{e}$ is a fundamental parameter for 98 conservation biologists (Frankham 1995), which links population dynamics and underlying 99 evolutionary processes (Hare et al. 2011). Indeed, $N_{e}$ is related to different ecological drivers 100 (e.g. population demographic parameters, life-history traits and mating systems; see Nunney 101 1993; Hedrick 2005; Nunney 1993; Waples 2006) and it gives insights into the evolutionary 102 potential of a population (Hare et al. 2011). A drawback is that $N_{e}$ is notoriously difficult to 
103 estimate in wild populations (Gilbert \& Whitlock 2015) and the relationship between $N_{e}$ and its 104 ecological drivers is still a matter of debate (Karl 2008; Pearse \& Anderson 2009).

105 In the marine realm, the majority of invertebrates are characterized by bentho-pelagic life cycles 106 with a dispersive larval phase and a sessile adult phase. The reproduction usually involves $\mathrm{d}$ 107 long-lived, late-maturing and highly fecund individuals following a promiscuous mating 108 strategy, in which any males mate with any females and vice versa (Karl 2008). As a by-product 109 of promiscuity, multiple paternity (i.e. siring of a female clutch by more than one male) is likely 110 to occur (e.g. Lasker, Gutiérrez-Rodríguez, Bala, Hannes, \& Bilewitch, 2008; Mokthar-Jamai 111 et_al. 2013; Warner et al. 2016). Marine invertebrates are also usually characterized by reduced $112 N_{e}$ values compared to their high census population size $\left(N_{c}\right)$ (Hauser \& Carvalho 2008; Hedrick 1132005 ; Hauser \& Carvalho 2008). This reduction was explained by a differential reproductive 114 success among individuals, the "sweepstakes reproductive success" hypothesis (Hedgecock 115 1994). Genetic imprints of sweepstake effects include a decrease in genetic diversity and an 116 increase of linkage disequilibrium and relatedness from adults to recruits, which should result 117 in a significant genetic differentiation between cohorts (Hedgecock \& Pudovkin 2011). While 118 multi-paternity and sweepstakes effect were demonstrated in different species (e.g. Christie, 119 Johnson, Stallings \& Hixon 2010; Selkoe, Gaines, Caselle; \& Warner; 2006; Christie, Johnson, 120 Stallings, \& Hixon, 2010), their ubiquity in the marine realm still remains to be characterized 121 (Hedgecock \& Pudovkin 2011). Moreover, From a broader perspective, the impact of 122 population decline on those particular mating patterns and the consequences for the 123 evolutionary potential in marine invertebrates is are still poorly understood (but see Plough, 124 Moran, \& Marko, 2014; Xue, Zhang, \& Liu 2016). In the current environmental context, 125 understanding how to enhance the resilience of populations facing demographic decline is 126 urgently needed. 
127 Our The main objective here was to gain insights into the putative feedbacks between mating 128 patterns and demographic decline focusing on the Mediterranean red coral, Corallium rubrum. 129 Distributed in the western Mediterranean and neighbouring Atlantic Ocean (Zibrowius, 130 Monteiro-Marques_\&, Grasshoff, 1984), this precious octocoral with slow population 131 dynamics, shows unambiguous signs of population decline due to overfishing for its use in 132 jewelry and warming-induced mass mortality events (Garrabou et al. 2017; Montero-Serra, 133 Linares, Doak, Ledoux, \& Garrabou, 2018). The red coral is a gonochoric brooder with internal 134 fertilization, balanced sex-ratio, annual reproductive cycle and late sexual maturity (i.e. 10 135 years of age) (Torrents \& Garrabou 2011; Torrents, Garrabou, Marschal, \& Harmelin, 2005; 136 Tsounis, Rossi, Aranguren, Gili, \& Arntz; 2006; Garrabou \& Torrents 2011). Significant 137 isolation by distance was demonstrated among colonies geo-referenced over half a square 138 metere confirming a limited effective dispersal (Aurelle \& Ledoux 2013; Costantini, Fauvelot, 139 \& Abbiati, 2007a,b; Ledoux et al. 2010a; Aurelle \& Ledoux 2013) and suggesting that 140 reproduction units are restricted in space and composed by of genetically related individuals 141 (Ledoux et al. 2010b). The subtle temporal genetic structure demonstrated among adults and 142 juveniles implied a low level of genetic drift at this spatial scale (Ledoux et al. 2010b). A lack 143 of temporal genetic structure was reported among recruits and juveniles coming from two 144 reproductive events in the same population (Costantini, Ruigiu, Cerrano, \& Abbiati, 2018). 145 While these studies shed new light on the reproduction of the red coral, a formal genetic 146 characterization of the mating pattern is still essentially lacking. Moreover, the putative impacts 147 of population decline on en the-reproductienve pattern remain to be tested.

148 Here, fFocused for the very first time oin the larval phase in the red coral-Corallium rubrum, 149 we focused on the larval phase tothis study aims to: i) genetically characterize the mating 150 system with particular emphasisze on multipaternity and inbreeding; ii) test for the sweepstakes 151 reproductive success hypothesis by characterizing patterns of genetic diversity, relationships 
152 and temporal genetic structure among adults and larvae; and iii) estimate the strength of genetic 153 drift based on different estimators of the number of breeders $\left(N_{b}\right)$. To achieve these aims, we 154 developed-a synchronic approach (i.e. the analyses of variations among contrasted populations 155 at a given time) was developed by comparing the results of progeny arrays and sibship analyses 156 in two red coral populations with highly contrastinged demographic structure: a pristine-like 157 (Garrabou et al. 2017) and a declining population (Linares et al. 2012).

\section{MATERIALS AND METHODS}

\section{Sampling}

161 Corallium rubrum colonies were sampled by scuba-diving at two sites with similar habitat 162 features: Grotte Harmelin in Corsica (42.38 N, 8.54 E, France; HAR) and Pedra de Déu in 163 Medes Islands $\left(42.0461^{\circ} \mathrm{N}, 3.22477^{\circ} \mathrm{E}\right.$; Spain; DEU) (Figure- 1). HAR is one of the last 164 pristine-like shallow populations of red coral. It is characterized by the highest biomass of large165 sized colonies $(>10 \mathrm{~cm}$ in height) reported to date in the Mediterranean Sea with the co166 existence of colonies of different sizes resulting in high density (201 colonies- $\left.\mathrm{x} \mathrm{m}^{-2}\right)($ Garrabou 167 et al. 2017). In contrast DEU, while situated in the "Parc natural del Montgri, les Illes Medes i 168 el Baix Ter", shows signs of population decline-_with a shift in population size structure with 169 the absence of large-size colonies, and lower biomass and density (49.4 colonies $\mathrm{x} \_\mathrm{m}^{-2}$; 170 Garrabou unpublished data; Linares et al. 2012). The sampling was conducted in June 2013 at 171 the beginning of the annual reproduction period (Torrents \& Garrabou 2011; Tsounis et al. 172 2006; Santangelo et al. 2003). Small fragments (1 to $2 \mathrm{~cm}$ ) from 30 and 33 -adults with high 173 reproductive potential (height $>5 \mathrm{~cm}$; see Torrents, Garrabou, Marschal, \& Harmelin, 2005) 174 were randomly hand-collected over three square meteres in the two populations $(\mathrm{N}=30$ and $175 \mathrm{~N}=33$ in DEU and HAR, respectively). The fragments were preserved in $95 \%$ ethanol and 176 stored at $-80^{\circ} \mathrm{C}$ until sexing and DNA extraction. 
177 Sexing was conducted by dissecting polyps under a binocular microscope. When a female 178 colony was identified, 10 additional polyps were dissected and all the larvae were collected, 179 preserved in $95 \%$ ethanol and stored at $-80^{\circ} \mathrm{C}$ until DNA extraction.

\section{DNA extraction, microsatellite genotyping, quality control and microsatellite characteristics}

182 DNA extractions and genotyping of eight microsatellites previously developed in this species 183 (Ledoux et al. 2010a) are detailed in Appendix A. MICRO-CHECKER 2.2.3 (Van Oosterhout 184 et al. 2004) was used to test scoring errors. Because null alleles and genotyping errors can bias parentage analyses (Dakin \& Avise 2004), we aimed to minimize their impact on the following 186 analysis-(see below). We fFirst, all the individuals with more than two null genotypes (i.e. no 187 amplification) were discarded-all the individuals with more than two null genotypes (i.e. no 188 amplification). Then, we conducted-a preliminary parentage analysis in COLONY 2.0.6.1 189 (Jones \& Wang 2010; see below for details) was conducted. Knowing the true maternal sibships 190 between females and larvae, we objective of this analyses was to tested whether the 191 information contained in the genotypes was sufficiently robust to reconstruct these relationships 192 without specifying the maternal sibships. We retained o- $\underline{\text { nly }}$ the larvae that were assigned with 193 a probability equal to 1 to their true mother were retained. The final dataset was composed 194 bycomprised 204 samples coming from two populations (DEU and HAR) and assigned to two 195 different stage-classes (adults [AD] and larvae [LAR:-]). In DEU, we analyzed 67 larvae (DEU196 LAR) from eight mothers and 30 adults (DEU-AD; 10 males and 20 females including the eight 197 mothers). In HAR, we analyzed 74 larvae (HAR-LAR) from 11 mothers and 67 larvae (DEU 198 LAR) from eight mothers in DEU and 33 adults (HAR-AD; 19 males and 14 females including 199 the 11 mothers) and 74 larvae (HAR LAR) from 11 mothers in HAR (Table 1). 
201 Genetic diversity analyses, long-term inbreeding and temporal genetic structure between 202 adults and larvae

203 Frequencies of null alleles were estimated for each locus within each stage-class (i.e. adults and

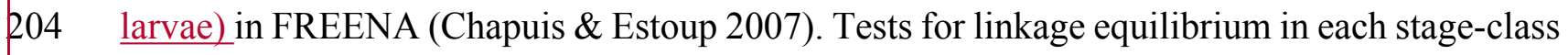
205 (i.e. adults and larvae)-were conducted in GENETIX 4.05 (Belkhir et al. 2004) using 1000 206 permutations. We computed $\underline{t} \underline{T}$ he observed heterozygosity $\left(H_{o}\right)$ and gene diversity $\left(H_{e}\right.$; Nei 207 1973) were computed for each stage-class in GENEPOP 4.1.4 (Rousset 2008). We used-ADZE 208 (Szpiech et al. 2008) was used to compute the allelic richness $\left(A r_{g}\right)$ using the rarefaction method 209 (Petit et al. 1998) with $g$, the minimum number of genes at a locus in a population, equals to 210 56. The values of $H_{e}$ and $\operatorname{Ar}_{(56)}$ were compared between stage-classes in each population using 211 Wilcoxon signed rank tests.

212 Because null alleles bias the estimation of $F_{I S}$, usedINEST (Chybicki \& Burczyk 2009)was 213 used under the Population Inbreeding Model to compute the $F_{I N E S T}$, an unbiased estimate of 214 inbreeding coefficient. A first full model accounting for null alleles, inbreeding and genotyping 215 failures was run for 200,000 iterations, a thinning of 100 and 50,000 burn-in. To test whether 216 inbreeding was a significant component of the model, we compared this model was compared 217 with a model without inbreeding based on the Deviance Information Criterion (DIC). The 218 model with the lower DIC was retained.

219 Temporal genetic differentiation was estimated based on pairwise $F_{S T}$ among adults and larvae 220 within each population using $\theta$, the Weir \& Cockerham's (1984) estimator of $F_{S T}$. Genotypic 221 differentiation was tested using an exact test with default parameters in GENEPOP.

\section{Mating system analysis}


225 Based on the maternal progeny arrays, computed-the multilocus outcrossing rate $\left(t_{m}\right)$ and 226 the single outcrossing rate $\left(t_{s}\right)$ were computed for each population (HAR: 11 families; DEU: 8 227 families) using the maximum likelihood method and Newton-Raphson iterations as 228 implemented MLTR v.3.2 (Ritland 2002). We adopted a $\underline{\text { A c conservative approach was adopted }}$ 229 and-excludinged Mic25 and Mic27, which showed the highest level of null alleles and 230 genotyping errors, respectively. The difference between $t_{m}-t_{s}$ was used to estimate the level of 231 instantaneous biparental inbreeding (mating among close relatives) in each population. In 232 addition, we estimated the correlated paternity $\left(\underline{r}_{(p)}\right)$ defined as the proportion of full sibs within 233 maternal progeny arrays was estimated for each population- $\left(r_{(p)}\right)$ defined as the proportion of 234 full sibs within maternal progeny arrays. The standard deviation and 95\% confidence intervals $235(95 \% \mathrm{CI})$ of each parameter were estimated using a bootstrap procedure by resampling families 2361000 times. These $95 \%$ CI were used to test whether the estimated values were different from $237 \quad 0$ and for comparison among sitespopulations.

\section{Characterization of the pattern of relationships}

239 The maximum-likelihood method implemented in COLONY 2.0.6.1 (Jones \& Wang 2009) was

240 used to reconstruct the pattern of relationships among larvae and to assign paternity in each 241 population accounting for genotyping errors (Wang 2004). We set the The levels of allelic 242 dropout were set to the frequencies of null alleles computed for each locus (see Wang 2004). 243 For all locius, the other type of genotyping errors was set to 0.01 , an upward estimation of error 244 rates based on the re-genotyping procedure (not shown). Known maternal sibs, the excluded 245 maternity and the excluded maternal sibs were defined. We conducted three-Three runs with 246 different seed numbers were conducted considering females and males as polygamous and 247 using the Full-Likelihood method with very high and very long likelihood precision and length 248 of run, respectively. The robustness of the results was tested using a reduced dataset of six 
249 microsatellites excluding Mic25 and Mic27. Because patterns of relationships were consistent 250 and robust among runs, we present the results obtained for one run only are shown.

\section{Sweepstakes reproductive success hypothesis}

Test of reproductive skew among putative fathers

254 In case of sweepstake effects, differential reproductive success among individuals is expected 255 (i.e. reproductive skew). We tested the The occurrence of differential reproductive success 256 among the males inferred with COLONY in each population was tested using the Nonacs 257 binomial skew index $B$ implemented in SKEW CALCULATOR (Nonacs 2000, 2003). $B$ ranges 258 from -1 to +2 . Random mating is observed for $B=0$; negative values suggest that reproduction 259 is more evenly distributed than expected while positive values correspond to a skew greater 260 than expected suggesting differential reproductive success among individuals. The one-tailed 261 p-value associated with $B$ in each site was computed with 5000 simulations. We then computed 262 the The $95 \%$ confidence interval of $B$ in each site was estimated.

Comparison of relatedness estimators among stage-classes

264 Sweepstake effects also induced an increase of genetic relatedness from reproductive adults to 265 their descendants. We thus computed the The levels of relatedness for each stage-class in each 266 population were computed using Lynch-Li moment-estimator (Lynch 1988; Li, Weeks; \& 267 Chakravarti; 1993; Lynch 1988) in COANCESTRY (Wang 2011). We tested the The 268 significance of the differences of the average relatedness between adults and larvae in each 269 population was tested using a bootstraps procedure (1000).

\section{Estimation of effective population size $\left(\mathrm{N}_{\mathrm{e}}\right)$ and relative impact of genetic drift}

272 According to the challenges linked to estimation of effective population size $\left(N_{e}\right)$ in long-lived 273 and iteroparous species (Waples 2010; Wang 2016), such as the red coral, we compute different 
274 different estimators of $N_{e}$ were computed (Hare et al. 2011). These computations, based on 275 larvae coming from a single reproductive event ${ }_{2}$ results in an estimation of effective number of 276 breeders $\left(N_{b}\right)$ instead of a "true" $N_{e}$. Empirical works suggested similar results between the two 277 parameters (e.g.; Beedee 2009; Duong, Scribner, Forsythe, Crossman, \& Baker-; 2013).

278 We estimated fourFour estimators of $N_{b}$ were computedusing: i) the sibship assignment method 279 (Wang 2009); ii) the standard linkage disequilibrium method (Hill 1981) with Waples' (2006) 280 correction under the random-mating model, excluding rare alleles with frequencies of less than 2810.02 and using a jackknife procedure to estimate confidence intervals (Waples \& Do 2008, 282 2010); iii) the method based on molecular coancestry (Nomura et al. 2008). We also computed 283 iv) moment-based F-statistics estimator (Waples 1989; Jorde \& Ryman 2007; Waples 1989) 284 considering a sampling plan I (see Waples 2005 for details) and that the adults and the larvae 285 in each population were separated by one generation. The last three estimators were computed 286 using NeEstimator v.2 (Do et al. 2014). Following Waples \& Do (2010) and Riquet et al. 287 (2016), an unweighted harmonic mean of $N_{b}$ in each population was computed to obtain an 288 overall estimate of effective population size.

\section{RESULTS}

291 Microsatellite characteristics, stage-class genetic diversity, long-term inbreeding and 292 temporal genetic structure

293 No evidence of scoring errors due to stuttering or large allele dropout was found. In the two 294 populations, all loci were polymorphic (p-value $<0.01)$. The frequency of null alleles $(r)$ was 295 between 0.09 for HAR-AD and HAR-LAR and 0.12 for DEU-AD and DEU-LAR (mean over 296 populations $\pm \mathrm{SE}=0.1 \pm 0.02)$. Observed heterozygosity values $\left(H_{o}\right)$ were between 0.49 for 297 DEU-LAR and 0.53 for HAR-AD (mean over populations $\pm \mathrm{SE}=0.51 \pm 0.01$ ). The gene 298 diversity $\left(H_{e}\right)$ ranged between 0.65 (HAR-LAR) and 0.72 (DEU-AD) (mean over populations 
$299 \pm \mathrm{SE}=0.68 \pm 0.03)$. Regarding $A r_{(56)}$, the highest and lowest values were observed for DEU$300 \mathrm{AD}(11.1)$ and HAR-LAR (9) (mean $A r_{(56)}$ over samples $\left.\pm \mathrm{SE}=9.9 \pm 1.03\right)$. None of the 301 Wilcoxon signed ranked tests conducted to compare $H_{e}$ and $A r_{(56)}$ among adults and larvae in 302 each population wereas significant after FDR correction for multiple tests (Table 1). $F_{I N E S T}$

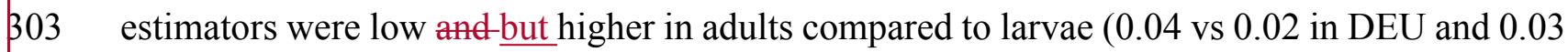
304 vs. 0.01 in HAR). In all the cases, the model without inbreeding showed the lowest DIC 305 suggesting a lack of inbreeding (results not shown).

306 The two temporal $F_{S T}$ s were low (0.002 for DEU-AD vs. DEU-LAR and 0.005 for HAR-AD 307 vs. HAR-LAR) but significant ( $\mathrm{p}$-values $<0.05$ ).

Mating system analyses

Instantaneous biparental inbreeding and correlated paternity

311 The multilocus outcrossing rates $\left(t_{m}\right)$ were close to 1 in both populations as expected in strictly 312 outcrossing species. The single outcrossing rate $\left(t_{s}\right)$ was 0.78 for DEU and 0.74 for HAR 313 resulting in a higher signal of biparental inbreeding $\left(t_{m}-t_{s}\right)$ in DEU $(0.21 ; 95 \% \mathrm{CI}=0.13-0.45)$ 314 than in HAR $(0.17 ; 95 \% \mathrm{CI}=0.07-0.26)$. Based on the $95 \%$ CIs, The the estimates of 315 biparental inbreeding were significantly different from 0 in the two populations (DEU: $95 \% \mathrm{CI}$

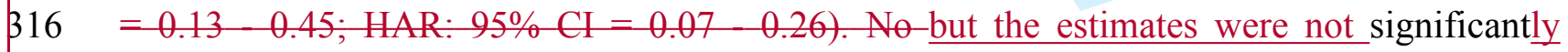
317 difference-different was observed-between the two populations-as the two $95 \%$ CI overlapped. 318 Estimates of correlated paternity were $0.23(95 \% \mathrm{CI}=0.09-0.46)$ for DEU and 0.12 for HAR $319(95 \% \mathrm{CI}=-0.03-0.25)$. The two estimates were not significantly different based on their $95 \%$ 320 CI (Table 2). Pattern of relationships

322 Considering only relationships with a probability $>0.8$, in DEU, we obtained-six full-sib dyads 323 and 246 half-sib dyads over the 2211 putative relationships were retained, corresponding to $3240.27 \%$ and $11.12 \%$, respectively. The total number of fathers was 32 . In HAR, we observed 
325 two full-sib dyads and 235 half-sib dyads over the 2701 putative relationships were observed, corresponding to $0.07 \%$ and $8.7 \%$, respectively. The total number of fathers was 43 . Evidence of multiple paternity was found in all the families from the two populations. The number of fathers for each family in DEU ranged from 6 to 10, with a mean value of $7.5 \pm 1.5$ fathers. In HAR, the number of fathers for each family varied from 2 to 10 , with a mean value of $6.5 \pm 2.4$ 330 fathers. The putative fathers were involved in multiple mating events producing 1 to 5 larvae, with a mean value of $2.1 \pm 1.1$ in DEU and a mean value of $1.9 \pm 1$ in HAR (Figure 2).

\section{Sweepstakes reproductive success hypothesis}

\section{Reproductive skew among putative fathers}

335 Although the number of larvae per putative father ranged from 1 to 5, the skew observed among 336 males was not significantly different from random expectations in the two populations $(B=-$ $3370.0057, \mathrm{p}$-value $=0.973$ in $\mathrm{DEU} ; \mathrm{B}=-0.008 \mathrm{p}$-value $=1$ in HAR). This suggests a similar 338 contribution of the different fathers to the pool of larvae.

340 Mean estimates of relatedness based on the Lynch-Li moment-estimator ranged from $-8.84^{*} 10^{-2}$ 341 in DEU-AD to $7.65 * 10^{-2}$ in HAR-LAR. The differences of mean relatedness between adults 342 and larvae were significant in the two populations (Table 3).

\section{Estimation of effective population size $\left(\mathbf{N}_{\odot}\right)$}

345 Based on the sibship assignment method, $N_{b}$ was 29 (95\%CI: 18-49) for DEU and 39 (95\%CI: 346 25-61) for HAR. The linkage disequilibrium and the molecular coalescent estimates of $N_{b}$ were 34738.3 (95 \%CI: 30-50) and 4.7 (95\%CI: 1.9-8.7) in DEU and 35.9 (95\%CI: 29.1-45) and infinity

348 in HAR, respectively. The estimates of $N_{b}$ obtained with the temporal method were 25.5 (95 
349 \%CI: 17.4 - 35) in DEU and 34 (95 \%CI: 22.6 - 47.7) in HAR. The resulting harmonic means 350 of $N_{b}$ were 12.8 for DEU and 48.2 for HAR (Table 4).

\section{DISCUSSION}

353 The impact of demographic decline on population dynamics and evolution is a central concern

354 for conservation biologists. This study, which is the first genetic characterization of the mating 355 system of an internal brooding octocoral-. In spite of a lack of statistically significant 356 differences in the mating patterns of the two populations, a higher biparental inbreeding and 357 correlated paternity combined with a lower number of breeders were reported in the declining 358 populationshows similar reproductive patterns between a pristine-like and a declining 359 population. suggesting that red coral may be relatively resilient to population decline. While 360 theese results may potentially be affected by the occurrence of null alleles, it is noteworthy that 361 the dataset was filtered to decrease their impact (e.g.; only mother/larvae pairs with assignment 362 probability $=1$ were retained). We also used a $\underline{A}$ broad set of complementary analyses relying 363 on different statistical methods was also used and, which-showed concordant results (ie.egg. 364 sibship reconstruction $v s$. progeny array analyses, four different $\mathrm{Nb}$ estimators). Moreover, 365 simulations considering different levels of genotyping errors demonstrated the robustness of 366 the sibship reconstruction method implemented in COLONY (Wang 2004). We thus consider 367 our results as relevant and we discuss below $\mathrm{t}$ Their implications of these results for the basic 368 ecological knowledge of the red coral and for its evolution in the context of population decline 369 is discussed below.

\section{Does multipaternity buffer long-term inbreeding?}

372 We-Memonstrate maltipaternity is likely the norm in the red coral. Indeed, the 19 progeny 373 arrays analyszzed were sired by more than one male as supported both by the sibship analyses 
374 in COLONY and by the correlation of paternity estimated in MLTR. Polyandry is expected in 375 promiscuous mating species and was previously demonstrated in one red coral population based 376 on kinship analyses among juveniles and adults (Ledoux et al. 2010b). The estimated mean 377 number of larvae per father inferred in COLONY over the two populations studied here (1.88 $378+/-0.9$ larvae / father) is in the same order as those previously reported in the same species $(2.3$ 379 +/- 0.8 offspring / parent; Ledoux et al. 2010b) and in another tropical octocoral Antillogorgia 380 elisabethae (1.42 +/- 0.7 larvae / father; Lasker, Gutiérrez-Rodríguez, Bala, Hannes, \& 381 Bilewitch, 2008) and slightly lower than in the Mediterranean Paramuricea clavata $(6.6+/-4.7$ 382 larvae / father; Mokhtar-Jamaï et al. 2013). Variations in the level of multiple paternity among 383 species are usual in marine invertebrates (e.g. Brante, Fernandez, \& Viard; 2011; Warner et al. 384 2016). While polyandry is a widespread strategy among organisms from sessile marine 385 invertebrates to social mammals and including wind_- pollinated plant and tree species 386 (Simmons 2005), its evolution remains a controversial issue (Yasui et al. 2016). Focusing on 387 sessile marine species in which polyandry is passive (i.e. females passively receive the gamete 388 from different males), the adaptive value is questioned. Multiple mating may simply be 389 correlated to the selective pressure increasing fertilization success when multiple individuals 390 are present (Johnson \& Yund 2007; Brante, Fernandez, \& Viard; 2011; Johnson \& Yund 2007). 391 Alternatively, the adaptive hypothesis lies on indirect genetic benefits for the females. 392 Polyandry may increase offspring survival enhancing in turn female reproductive fitness by 393 increasing the genetic diversity, and the viability or the competiveness of the offspring through 394 advantageous male genes (see Zeh \& Zeh 2000; Yasui \& Garcia-Gonzales 2016; Zeh \& Zeh $395 \underline{2000}$ for reviews).

396 While it is notoriously challenging to test for indirect genetic effects (Yasui \& Garcia-Gonzales 397 2016) and acknowledging the complexity of the interactions between mating system and 398 inbreeding (Frankham 1995), a decrease of inbreeding was also proposed as one of the indirect 
399 genetic benefits of multipaternity (Zeh \& Zeh 2000). Here, dementrated thathe -inbreeding 400 varied in function of the temporal scale. The progeny array approach supports significant level 401 of instantaneous biparental inbreeding (i.e. crossing between related mates). This result is in 402 accordance with the view of red coral populations as mosaics of spatially restricted breeding 403 units (< one square metere) composed by relatives (Ledoux et al. 2010b). In contrast, when 404 considering the multilocus inbreeding coefficients unbiased by null alleles $\left(F_{\text {INEST }}\right)$, which 405 estimate the combined effect of inbreeding depression (i.e. the fitness decrease observed in 406 related individuals) and biparental inbreeding over several generations, inbreeding was not 407 statistically supported. This absence of long-term inbreeding may appear surprising considering 408 the high and significant $F_{I S}$ values reported in previous studies (e. g. Ledoux et al. 2010a). 409 Nevertheless, these $F_{I S}$ values were likely biased by null alleles and Wahlund effect (Ledoux et 410 al. 2010a). Further analyses such as estimations of inbreeding coefficients on well-defined 411 cohorts (from larvae to recruits, juveniles and adults) and reproduction experiments in aquaria 412 should be envisaged to formally test a putative buffering effect of multipaternity on inbreeding 413 in the red coral.

415 Soft sweepstakes effect and low genetic drift in the red coral.

416 Interestingly, larvae production does not seem to be impacted by strong sweepstakes effects in 417 this species. None of the genetic diversity parameters tested wereas significantly different 418 between larvae and adults in the two populations. No linkage disequilibrium was reported in 419 the larvae although it is expected when a small number of individuals produced the next 420 generation. Moreover, while a significant increase of genetic relatedness was reported from 421 adults to larvae, the genetic differentiation between the two stage-classes in each population 422 was only marginally significant. The high polymorphism of the microsatellites used here may 423 partially explain these results (Hedgecock \& Pudovkin 2011). Nevertheless, theis absence of 
424 sweepstake effect is also supported by the lack of reproductive skews among the fathers inferred 425 with COLONY. Sweepstakes effect is expected in promiscuous sessile marine invertebrates 426 with larval phase (Hedegecock \& Pudovkin 2011) but eur resultsthe lack of sweepstake 427 observed here are is also supported by the null to low temporal differentiation previously 428 reported among juveniles and adults (Ledoux et al. 2010b) or recruits and juveniles (Costantini, 429 RigiuRugiu, Cerrano, \& Abbiati, 2018). This can be related to red coral life-history traits and 430 in particular, to the occurrence of mating among individuals from overlapping generations, 431 which may buffer temporal changes of allelic frequencies (Riquet, Le Cam, Fonteneau, \& 432 Viard, 2016). Comparing genetic characteristics among well-defined cohorts rather than stage433 classes is needed to assess this hypothesis.

434 The impact of a promiscuous mating system on $N_{e}$ and genetic drift has been previously debated 435 (Karl 2008; Pearse \& Anderson 2009). In species with a generation time higher greater than 10 436 years such as the red coral, multipaternity should only marginally impact $N_{e}$ (Lotterhos 2011). 437 While estimates of $N_{e}$ must be considered cautiously and considering that assumed 438 similarity between $N_{b}$ and $N_{e}$ was assumed here, our the results support moderate to high 439 numbers of breeders in the two populations. These values are concordant with the high $N_{e}$ 440 previously reported over a similar spatial area in the long-lived and polyandrous octocoral $P$. 441 clavata (Mokhtar-Jamaï et al. 2013). However, they contrast with the general trend in marine 442 species in which $N_{e}$ was shown to be orders of magnitude lower than the census population size $443\left(N_{c}\right)$ inducing and that genetic drift is usually stronger than expected (Hauser \& Carvalho 2008; 444 Hare et al. 2011; Hauser \& Carvalho 2008). In accordance with the lack of sweepstake effect 445 previously discussed, eur-the estimations of $N_{b}$ suggest genetic drift to be limited at the fine 446 spatial and temporal scales under survey. This result supports recent studies questioning the 447 ubiquity of low $N_{e} \mathrm{~s}$ in marine species (Hare et al. 2011; Riquet, Le Cam, Fonteneau, \& Viard, 448 2016). 
$450 \quad$ Does population decline impact red coral mating system and effective population size?

451 The site "Grotte Harmelin" (HAR) is considered as one of the last pristine-like shallow 452 population of red coral offering the pricelessopportunity to characterize the baseline population 453 dynamics in this species (Garrabou et al. 2017). Contrasting the results obtained in this 454 population with the results obtained in a declining population (DEU), we provides the first 455 insights into the consequences of demographic decline on mating system and effective 456 population size in the red coral.

457 None of the parameters (correlated paternity, biparental inbreeding and number of breeders) 458 estimated to compare the mating patterns between the two populations were significantly 459 different. This result contrasts with the positive correlation between population density and 460 mating pattern reported in copulating marine invertebrates (e.g., barnacles (Plough, Moran, \& 461 Marko 2014); marine snails (Xue, Zhang, \& Liu 2016)). In these species, the probability of 462 mate encounter increases with population density. The lack of differences among the two 463 populations is concordant with what was found between low and high-density populations in a 464 sperm-cast ascidian (Johnson \& Yund 2007). In sperm-cast species such as the red coral, the 465 spermatozoa may cross greater distances in the water column in low density populations 466 buffering the influence of density on mate interactions (e.g. Duminil et al. 2016). Nevertheless, 467 in spite of this lack of statistically significant differences between the two populations, all the 468 analyses suggest some negative consequences of demographic decline. A trend toward higher 469 biparental inbreeding and correlated paternity combined with a lower number of breeders is 470 observed in the declining compared to the pristine-like population. Accordingly, we 471 hypothesized the expected increase in genetic drift, due the lower mate density in DEU 472 compared to HAR, to be balanced to some point by an increase of male gamete flow. While the 473 hypothesized buffering effect of male gamete flow remains to be formally tested in the red 
474 coral, it is likely subtle and limited as supported by the negative trend observed in the declining 475 population. The characterization of spatial genetic structures in populations with contrasted 476 demographic patterns and the inference of related demographic parameters (e.g. effective 477 dispersal) is required to go further in this hypothesis and to improve our understanding of the 478 feedbacks between demographic decline and mating patterns in the red coral.

479 In spite of the trend toward higher inbreeding and genetic drift in the declining population 480 (DEU), none of the parameters (correlated paternity, biparental inbreeding and number of 481 breeders) estimated to compare the mating patterns between the two populations were 482 significantly different. Contrasting with the positive correlation between population density and 483 mating pattern reported in copulating marine invertebrates (e.g., barnacles in Plough, Moran, 484 \& Marke, 2014; marine snails in Xue, Zhang, \& Liu 2016), this result is concordant with the 485 tack of differences found between low and high-density populations in a spermeast ascidian 486 (Johnson \& Yund 2007). In copulating species, the probability of mate encounter increases with 487 population density. In spermeast species, the spermatozoa may cross higher distances in the 488 water column in low density population buffering the influence of density on mate interactions. 489 Such effect has been previously demonstrated in other long lived sessile species with similar 490 reproductive strategies such as tropical trees in which pollen dispersal distance increases in 491 declining population (e.g. Duminil et al. 2016). Based on these results, we propose that the 492 expected increase in genetic drift due the lower mate density in DEU compared to HAR may 493 be balanced by an increase of male gamete flow. The characterization of spatial genetic 494 structures in populations with contrasted demographic patterns and the inference of related 495 demographic parameters (e.g., effective dispersal) is thus a critical step to improve our 496 understanding of the feedbacks between demographic decline and mating patterns in the red 497 eoral. This should also allow the identification of putative demographic thresholds beyond 498 which the buffering effect of gamete dispersal will be inefficient. 
$\begin{array}{ll}499 & \\ 500 & \\ 501 & \text { Overall, this study suggests the occurrence of subtle feedbacks between demographic and } \\ 502 & \text { reproductive patterns at in red coral populations. In complement to other processes (e.g. re- } \\ 503 & \text { growth of damaged colonies; see Montero-Serra et al. 2015), these feedbacks may partially } \\ 504 & \text { explain the long-term persistence of red coral populations in spite of the millennial fishing } \\ 505 & \text { pressure. They are likely to provide a borrowed time (sensu Hughes, Linares, Dakos, van de } \\ 506 & \text { Leemput, \& van Nes 2013) for the management and conservation of this threatened species. } \\ 507 & \text { Nevertheless, the negative trend reported in the declining population unambiguously supports } \\ 508 & \text { the maintenance of high density of reproductive colonies, and accordingly the diminution of } \\ 509 & \text { direct anthropogenic pressures (e.g. fishing), as a prerequisite to maintain functional red coral } \\ 510 & \text { populations. are resilient to some levels of population decline potentially due to an increase of } \\ 511 & \text { spermatozoa dispersal. This may potentially explain their long term persistence in spite of the } \\ 512 & \text { millennial fishing pressure and it provides a borrowed time (sensu Hughes, Linares, Dakos, van } \\ 513 & \text { de Leemput, \& van Nes, 2013) for the management and conservation of this threatened species. } \\ 514 & \end{array}$ 


\section{ACKNOWLEDGEMENTS}

532 Funding was provided by the Fundação para a Ciência e a Tecnologia (FCT)

533 (UID/Multi/04423/2019), the Spanish MINECO (CGL2012-32194), the TOTAL Foundation

534 PERFECT project, the MIMOSA project funded by the foundation Prince Albert II de

535 Monaco, and the European Union's Horizon 2020 research and innovation program under 536 grant agreement $N^{\circ} 689518$ (MERCES). This output reflects only the author's view and the 537 European Union cannot be held responsible for any use that may be made of the information 538 contained therein

539 JBL was supported by a postdoctoral grant (SFRH/BPD/74400/2010) from Fundação para a 540 Ciência e a Tecnologia (FCT), CL by a Ramon y Cajal (RyC-2011-08135)-and-, IMS by a FPI 541 grant (BES-2013-066150) and SC by research project SGR 622 (GRBIO) from the

542 Departament d' Economia i Coneixement de la Generalitat de Catalunya and (PGC2018543 095931-B-I00) MINECO (Spain).

544 Genotyping was performed at the Genome Transcriptome Facility of Bordeaux (grants from 545 the Conseil Régional d'Aquitaine $\mathrm{n}^{\circ} 20030304002 \mathrm{FA}$ and 20040305003FA, from the 546 European Union FEDER n²003227 and from Investissements d'Avenir ANR-10-EQPX-16$54701)$. 


\section{4}

555

556

557

558

559

560

561

562

563

564

565 REFERENCES

566

567

568

569

570

571

572

573

574

575

576

577

578

579

580

581

582

583

584

585

586

587
Aurelle, D., \& Ledoux, J.-B. (2013). Interplay between isolation by distance and genetic clusters in the red coral Corallium rubrum: Insights from simulated and empirical data. Conservation Genetics, 14(3), 705-716.

Ayre, DJ., \& Miller, K. (2006). Random mating in the brooding coral Acropora palifera. Marine Ecology Progress Series, 148 (8), 876-888.

Beebee, T_J_C. (2009). A comparison of single-sample effective size estimators using empirical toad (-Bufo calamita-) population data: genetic compensation and population size-genetic diversity correlations. Molecular Ecology, 18(23), 4790-4797.

Brante, A., Fernandez, M., \& Viard, F. (2011). Microsatellite evidence for sperm storage and extreme multiple paternity in the protrandous gastropod Crepidula coquimbensis. Journal of Experimental Marine Biology and Ecology, (396), 83-88.

Bruckner, A. (2009). Rate and extent of decline in Corallium (pink and red coral) populations: existing data meet the requirements for a CITES Appendix II listing. Marine Ecology Progress Series, 397, 319-332.

Charlesworth, B. \& Willis, J.H. (2009). Fundamental concepts in genetics: effective population size and patterns of molecular evolution and variation. Nature Reviews. Genetics, 10(3), 195-205.

Christie, M.R., Johnson, D.W., Stallings, C.D., and Hixon, M.A. (2010). Self-recruitment and sweepstakes reproduction amid extensive gene flow in a coral-reef fish. Molecular Ecology, 19(5), 1042-1057.

Costantini, F., Fauvelot, C., \& Abbiati, M. (2007a). Fine-scale genetic structuring in Corallium rubrum: Evidence of inbreeding and limited effective larval dispersal. Marine 
602

603

604

605

606

607

608

609

610

611

612

613

614

615

616

617

618

619

620

621

622

623

624

625

626

627

628

629

630

631

632

633

634

635

636

637

Ecology Progress Series, 340, 109-119.

Costantini, F., Fauvelot, C., \& Abbiati, M. (2007b). Genetic structuring of the temperate gorgonian coral (Corallium rubrum) across the western Mediterranean Sea revealed by microsatellites and nuclear sequences. Molecular Ecology, 16(24), 5168-5182.

Costantini, F., RigiuRugiu, L., Cerrano, C., \& Abbiati, M. (2018). Living upside down: patterns of red coral settlement in a cave.

PeerJ 6:e4649 https://doi.org/10.7717/peerj.4649.

Do, C., Waples, R.S., Peel, D., Macbeth, G.M., Tillett, B.J., \& Ovenden, J.R. (2014). NeEstimator v2: re-implementation of software for the estimation of contemporary effective population size ( $\left.\mathrm{N}_{-e_{-}^{-}}\right)$from genetic data. Molecular Ecology Resources, 14(1), 209-214.

Duminil, J., Daïnou, K., Kaviriri, D.K., Gillet, P., Loo, J., Doucet, J.L., \& Hardy, O.J. (2016). Relationships between population density, fine-scale genetic structure, mating system and pollen dispersal in a timber tree from African rainforests. Heredity, 116(3), 295-303.

Dunlop, E.S., Eikeset, A.M., \& Stenseth, N.C. (2015). From genes to populations: how fisheries-induced evolution alters stock productivity. Ecological Applications, 25(7), 1860-1868.

Duong, T.Y., Scribner, K.T., Forsythe, P.S., Crossman, J., \& Baker, E. (2013). Interannual variation in effective number of breeders and estimation of effective population size in long-lived iteroparous lake sturgeon (Acipenser fulvescens). Molecular Ecology, 22(5), 1282-1294.

Ferrière R., Dieckmann U., \& Couvet D. (2004). Evolutionary Conservation Biology. (Camb Univ Press). Cambridge.

Frankham, R. (1995). Conservation Genetics. Annual Review of Genetics, 29(1), 305-327.

Frankham, R., Bradshaw, C.J.A., \& Brook, B.W. (2014). Genetics in conservation management: Revised recommendations for the 50/500 rules, Red List criteria and population viability analyses. Biological Conservation, 170, 56-63.

Garrabou, J., Coma, R., Bensoussan, N., Bally, M., Chevaldonné, P., Cigliano, M., ... Cerrano, C. (2009). Mass mortality in Northwestern Mediterranean rocky benthic communities: Effects of the 2003 heat wave. Global Change Biology, 15, 1090-1103.

Garrabou, J., Sala, E., Linares, C., Ledoux, J.-B., Montero-Serra, I., Dominici, J.-M., ... Harmelin, J.-G. (2017). Re-shifting the ecological baseline for the overexploited Mediterranean red coral. Scientific Reports, 7, 42404.

Gilbert, K.J., \& Whitlock, M.C. (2015). Evaluating methods for estimating local effective population size with and without migration. Evolution, 69(8), 2154-2166.

Hare, MP., Nunney, L., Schwartz, MK., Ruzzante, DE., Burford, M., Waples, RS., ... Palstra, F. (2011). Understanding and estimating effective population size for practical application in marine species management. Conservation Biology, 25(3), 438-4449.

Hauser, L., \& Carvalho, G.R. (2008). Paradigm shifts in marine fisheries genetics: ugly hypotheses slain by beautiful facts. Fish and Fisheries, 9(4), 333-362.

Hedgecock, D. (1994). Does variance in reproductive success limit effective population size of marine organisms? Genetics and evolution of aquatic organisms A.Beaumont Ed. (Chapman and Hall). London .

Hedgecock, D., \& Pudovkin, A.I. (2011). Sweepstakes reproductive success in highly fecund marine fish and shellfish: a review and commentary. Bulletin of Marine Science, 87(4), 971-1002.

Hedrick, P. (2005). Large variance in reproductive success and the $N_{e} / N$ ratio. Evolution; International Journal of Organic Evolution, 59(7), 1596-1599. Retrieved from

Hill, WG. (1981). Estimation of effective population size from data on linkage disequilibrium. Genetical Research, 38(3), 209. 
638 Hughes, T.P., Linares, C., Dakos, V., van de Leemput, I.A., \& van Nes, E.H. (2013). Living

639

640

641

642

643

644

645

646

647

648

649

650

651

652

653

654

655

656

657

658

659

660

661

662

663

664

665

666

667

668

669

670

671

672

673

674

675

676

677

678

679

680

681

682

683

684

685

686

687 dangerously on borrowed time during slow, unrecognized regime shifts. Trends in Ecology and Evolution, 28(3), 149-155.

Johnson, SL., \& Yund, P.O. (2007). Variation in multiple paternity in natural populations of a free-spawning marine invertebrate. Molecular Ecology, 16(15), 3253-3262.

Jones, O.R., \& Wang, J. (2010). Molecular marker-based pedigrees for animal conservation biologists. Animal Conservation, 13(1), 26-34.

Jorde, P.E., \& Ryman, N. (2007). Unbiased eEstimator for gGenetic $\underline{\text { d}}$ Đrift and eEffective pPopulation s Size. Genetics, 177(2), 927-935.

Karl, S.A. (2008). The effect of multiple paternity on the genetically effective size of a population. Molecular Ecology, 17(18), 3973-3977.

Lasker, H., Gutiérrez-Rodríguez, C., Bala, K., Hannes, A., \& Bilewitch, J. (2008). Male reproductive success during spawning events of the octocoral Pseudopterogorgia elisabethae. Marine Ecology Progress Series, 367, 153-161.

Ledoux, J.-B., Garrabou, J., Bianchimani, O., Drap, P., Féral, J.-P., \& Aurelle, D. (2010). Fine-scale genetic structure and inferences on population biology in the threatened Mediterranean red coral, Corallium rubrum. Molecular Ecology, 19(19), 4204-4216.

Ledoux, J.-B., Mokhtar-Jamaï, K., Roby, C., Féral, J.-P., Garrabou, J., \& Aurelle, D. (2010). Genetic survey of shallow populations of the Mediterranean red coral [Corallium rubrum (Linnaeus, 1758)]: New insights into evolutionary processes shaping nuclear diversity and implications for conservation. Molecular Ecology, 19(4), 675-690.

Li, C., Weeks, D., \& Chakravarti, A. (1993). Similarity of DNA fingerprints due to chance and relatedness. Human Heredity, 43, 45-52.

Linares, C., Garrabou, J., Hereu, B., Diaz, D., Marschal, C., Sala, E., \& Zabala, M. (2012). Assessing the effectiveness of marine reserves on unsustainably harvested long-lived sessile invertebrates. Conservation Biology, 26(1), 88-96.

Lotterhos, KE. (2011). The context-dependent effect of multiple paternity onf effective population size. Evolution, 65(6), 1693-1706.

Lynch, M. (1988). Estimation of relatedness by DNA fingerprinting. Molecular Biology and Evolution, 5(5), 584- 599.

McCauley, D.J., Pinsky, M.L., Palumbi, S.R., Estes, JA., Joyce, FH., \& Warner, RR. (2015). Marine defaunation: animal loss in the global ocean. Science, 347(6219), 1255641.

Miller, KJ., \& Ayre, DJ. (2008). Population structure is not a simple function of reproductive mode and larval type: insights from tropical corals. The Journal of Animal Ecology, 77(4), 713-724.

Mokhtar-Jamai, K., Coma, R., Wang, J., Zuberer, F., Feral, J.-P., \& Aurelle, D. (2013). Role of evolutionary and ecological factors in the reproductive success and the spatial genetic structure of the temperate gorgonian Paramuricea clavata. Ecology and Evolution, 3(6), 1765-1779.

Montero-Serra, I., Linares, C., Doak, DF., Ledoux, J.-B., \& Garrabou, J. (2018). Strong linkages between depth, longevity and demographic stability across marine sessile species. Proceedings of the Royal Society serie B, 285(1873), 1765-1777.

Nomura, T. (2008). Estimation of effective number of breeders from molecular coancestry of single cohort sample. Evolutionary Applications, 1(3), 462-74.

Nonacs, P. (2000). Measuring and using skew in the study of social behavior and evolution. American Naturalist, 156, 577-589.

Nonacs, P. (2003). Measuring the reliability of skew indices: is there one best index? Animal Behaviour, 65, 615-627.

Nunney, L. (1993). The Influence of mating system and overlapping generations on effective population size. Evolution, 47(5), 1329-1341. 
688 Pearse, D.E., \& Anderson, E.C. (2009). Multiple paternity increases effective population size. Molecular Ecology, 18(15), 3124-3127.

Pinsky, M.L., \& Palumbi, S.R. (2014). Meta-analysis reveals lower genetic diversity in overfished populations. Molecular Ecology, 23, 29-39.

Plough, LV, Moran, A., \& Marko, P. (2014). Density drives polyandry and relatedness influences paternal success in the Pacific gooseneck barnacle, Pollicipes elegans. BMC Evolutionary Biology, 14(1), 81.

Riquet, F., Le Cam, S., Fonteneau, E., \& Viard, F. (2016). Moderate genetic drift is driven by extreme recruitment events in the invasive mollusk Crepidula fornicata. Heredity, $117(1), 42-50$.

Ritland, K. (2002). Extensions of models for the estimation of mating systems using $\mathrm{n}$ independent loci. Heredity, 88(4), 221-228.

Rousset, F. (2008). genepop'007: a complete re-implementation of the genepop software for Windows and Linux. Molecular Ecology Resources, 8(1), 103-106.

Santangelo, G., Carletti, E., Maggi, E. \& Bramanti L. (2003). Reproduction and population sexual structure of the overexploited Mediterranean red coral Corallium rubrum. Marine Ecology Progress Series, 248, 99-108.

Selkoe, K.A., Gaines, S.D., Caselle, J.E., \& Warner, R.R. (2006). Current shifts and kin aggregation explain genetic patchiness in fish recruits. Ecology, 87(12), 3082-3094.

Serbezov, D., Jorde, P.E., Bernatchez, L., Olsen, E.M., \& Vøllestad, L.A. (2012). Life history and demographic determinants of effective/census size ratios as exemplified by brown trout (Salmo trutta). Evolutionary Applications, 5(6), 607-618.

Simmons, LW. (2005). The Evolution of polyandry: Sperm competition, sperm selection, and offspring viability. Annual Review of Ecology, Evolution, and Systematics, 36(1), 125 146.

Spielman, D., Brook, BW., \& Frankham, R. (2004). Most species are not driven to extinction before genetic factors impact them. Proceedings of the National Academy of Sciences, 101(42), 15261-15264.

Torrents, O., \& Garrabou, J. (2011). Fecundity of red coral Corallium rubrum (L.) populations inhabiting in contrasting environmental conditions in the NW Mediterranean. Marine Biology, 158(5), 1019-1028.

Torrents, O., Garrabou, J., Marschal, C., \& Harmelin, J.-G. (2005). Age and size at first reproduction in the commercially exploited red coral Corallium rubrum (L.) in the Marseilles area (France, NW Mediterranean). Biological Conservation, 121, 391-397.

Tsounis $\mathrm{G}_{.}$, Rossi S., Aranguren $\mathrm{M}_{\dot{.}}$, Gili J-M., \& Arntz W. (2006) Effects of spatial variability and colony size on the reproductive output and gonadal development cycle of the Mediterranean red coral (Corallium rubrum L.). Marine Biology, 148, 513-527.

Wang, J. (2004) Sibship reconstruction from genetic data with typing errors. Genetics, 166(4), 1963-1979.

Wang, J. (2011). Coancestry: a program for simulating, estimating and analysing relatedness and inbreeding coefficients. Molecular Ecology Resources, 11(1), 141-145.

Wang, J. (2016). A comparison of single-sample estimators of effective population sizes from genetic marker data. Molecular Ecology, 25(19), 4692-4711.

Waples, R.S. (1989). A generalized approach for estimating effective population size from temporal changes in allele frequency. Genetics, 121(2), 379- 391 .

Waples, R.S. (2005). Genetic estimates of contemporary effective population size: to what time periods do the estimates apply? Molecular Ecology, 14(11), 3335-3352.

Waples, R.S. (2006). A bias correction for estimates of effective population size based on linkage disequilibrium at unlinked gene loci. Conservation Genetics, 7(2), 167-184.

Waples, R.S. (2010). Spatial-temporal stratifications in natural populations and how they 
742

743

744

745

746

747

748

749

750

751

752

753

754

755

756

757

758

759

760

761

762

763

764

765

766 affect understanding and estimation of effective population size. Molecular Ecology Resources, 10(5), 785-796.

Waples, R.S., \& Do, C. (2008). ldne : a program for estimating effective population size from data on linkage disequilibrium. Molecular Ecology Resources, 8(4), 753-756.

Waples, R.S., \& Do, C. (2010). Linkage disequilibrium estimates of contemporary $N_{e}$ using highly variable genetic markers: a largely untapped resource for applied conservation and evolution. Evolutionary Applications, 3(3), 244-262.

Warner, R., Kaidonis, M., Dun, O., Rogers, K., Shi, Y., Nguyen, TTX., \& Woodroffe, CD. (2016). Opportunities and challenges for mangrove carbon sequestration in the Mekong River Delta in Vietnam. Sustainability Science, 11(4), 661-677.

Weir, BS., \& Cockerham, CC. (1984). Estimating F-Statistics for the Analysis of Population Structure. Evolution, 38(6), 1358.

Wright, S. (1931). Evolution in mendelian populations. Genetics, 16(2), 97-159.

Xue, D.-X., Zhang, T., \& Liu, J.-X. (2016). Influences of population density on polyandry and patterns of sperm usage in the marine gastropod Rapana venosa. Scientific Reports, 6(1), 23461.

Yasui, Y., \& Garcia-Gonzalez, F. (2016). Bet-hedging as a mechanism for the evolution of polyandry, revisited. Evolution, 70(2), 385-397.

Zeh, DW., \& Zeh, JA. (2000). Reproductive mode and speciation: the viviparity-driven conflict hypothesis. BioEssays, 22(10), 938-946.

Zibrowius, H., Monteiro-Marques, V., \& Grasshoff, M. (1984). La répartition du Corallium rubrum dans l'Atlantique (Cnidaria: Anthozoa: Gorgonaria). Téthys, 11, 163-170.

\section{Authors' contributions:}

JBL, CL and JG designed the study. CL, CCB and IMS performed sexing and larvae collection. JBL, PLS, SF and CCB performed laboratory work. JBL, SF and SC analyzed the data. JBL and SF wrote the manuscript with input from all authors. All authors approved the manuscript.

\section{Data accessibility:}

Microsatellite genotypes will be made available on Dryad. 


\section{Supporting information:}

781 Additional information may be found in the online version of the article:

782

783

\section{Appendix A: DNA extraction and microsatellite genotyping}

784 Conflict of interest: No conflict of interest to declare.

785

786

787

788

789

790

791

792

793

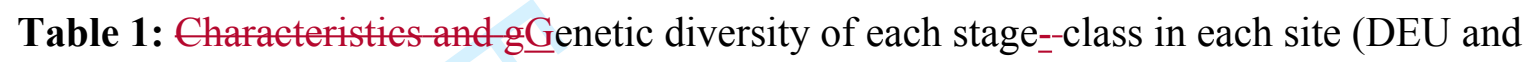

HAR). $N$ : number of individuals; $r$ : frequency of null alleles; $H_{o}$ : observed heterozygosity;

$H_{e}$ : gene diversity; $A r_{(56)}:$ rarefied allelic richness considering a minimum of 56 genes at a

locus in a population; $F_{I N E S T}$ : estimate of inbreeding coefficient unbiased by null alleles.

\begin{tabular}{|c|c|c|c|c|c|c|c|}
\hline & $N$ & $r$ & $H_{o}$ & $H_{e}$ & $A r$ & $A r_{(56)}$ & $F_{I N E S T}$ \\
\hline DEU-AD & 30 & 0.12 & 0.52 & 0.72 & 11.25 & 11.1 & 0.04 \\
\hline DEU-LAR & 67 & 0.12 & 0.49 & 0.69 & 11 & 9.1 & 0.02 \\
\hline HAR-AD & 33 & 0.09 & 0.53 & 0.66 & 10.62 & 10.3 & 0.03 \\
\hline HAR-LAR & 74 & 0.09 & 0.52 & 0.65 & 11.62 & 9 & 0.01 \\
\hline
\end{tabular}




\section{5}

796 Table 2: Mating system characteristics for each site. $t_{m}$ : multilocus outcrossing rate; $t_{s}$ : single

797 outcrossing rate; $t_{m}-t_{s}$ : level of biparental inbreeding; $r_{(p)}$ : correlated paternity. The $95 \%$

798 confidence intervals $(95 \% \mathrm{CI})$ of each parameter was estimated by resampling families 1000

799 times.

800

801

\begin{tabular}{|l|l|l|l|l|}
\cline { 2 - 5 } \multicolumn{1}{c|}{} & $\begin{array}{c}\text { Multilocus outcrossing } \\
\text { rate }\left(t_{m}\right) \text { and }[95 \% \mathrm{CI}]\end{array}$ & $\begin{array}{c}\text { Single outerossing } \\
\text { rate }\left(t_{s}\right) \text { and }[95 \% \\
\mathrm{CI}]\end{array}$ & $\begin{array}{c}\text { Biparental } \\
\text { inbreeding } \\
{[\text { and } 95 \% \mathrm{CI}]}\end{array}$ & $\begin{array}{c}\text { Correlated paternity } \\
r_{(p)} \text { and }[95 \% \mathrm{CI}]\end{array}$ \\
\hline $\mathrm{DEU}$ & $0.99[0.95 ; 1.2]$ & $0.78[0.64 ; 0.89]$ & $0.21[0.13 ; 0.45]$ & $0.23[0.09 ; 0, .46]$ \\
\hline $\mathrm{HAR}$ & $0.94[0.86 ; 1]$ & $0.77[0.67 ; 0.88]$ & $0.17[0.07 ; 0.26]$ & $0.12[-0.03 ; 0.25]$ \\
\hline
\end{tabular}

802

803

804

805

806

807

808

809

810

811

812

813

814

815

816 
817 Table 3: Estimates of relatedness for each stage-class in each population using the $L L$ : Lynch-

818 Li moment-estimator of relatedness. Observed value corresponds to the difference between

819 adults and larvae in each population. The significance of the differences among the two stage-

820 classes was tested using on 1000 bootstraps. Significant differences are shown in bold.

\begin{tabular}{|c|c|c|}
\hline & Lynch-Li & $\begin{array}{c}\text { Observed Value and } 95 \% \\
\text { CI }\end{array}$ \\
\hline $\begin{array}{l}\text { DEU- } \\
\text { AD }\end{array}$ & $8.84 \underline{x}-10$ & \\
\hline $\begin{array}{l}\text { DEU- } \\
\text { LAR }\end{array}$ & $2.31 \underline{x} * 10^{-}$ & $\begin{array}{c}9 \underline{x} * 10^{-2} \\
{\left[-2.5 x * 10^{-2} ; 2.51 * x 10^{-2}\right]}\end{array}$ \\
\hline $\begin{array}{l}\text { HAR- } \\
\text { AD }\end{array}$ & $\begin{array}{l}5.28 \times \underline{x} * 10^{-} \\
\end{array}$ & \\
\hline $\begin{array}{l}\text { HAR- } \\
\text { LAR }\end{array}$ & ${ }_{2}^{7.65} \underline{x}^{*} 10^{-}$ & $\begin{array}{c}2.37 \underline{x} * 10^{-2} \\
{\left[-2.55 x * 10^{-2} ; 1.95 x * 10^{-2}\right]}\end{array}$ \\
\hline
\end{tabular}

823

824

825

826

827

828

829

830

831

832

833

834 


\section{5}

836

837 Table 4: Effective population size and $95 \%$ confidence interval (between brackets) computed

838 for each site using: i) the sibship assignment method; ii) the standard linkage disequilibrium

839 method; iii) the method based on molecular coancestry; and iv) the moment based F-statistics

840 methods.

841

842

843

\begin{tabular}{|c|c|c|c|c|c|}
\cline { 2 - 6 } \multicolumn{1}{c|}{} & $\begin{array}{c}\text { Sibship } \\
\text { assignment } \\
\text { method } \\
\text { (Wang } \\
2009)\end{array}$ & $\begin{array}{c}\text { Standard linkage } \\
\text { disequilibrium } \\
\text { method } \\
\text { (Hill 1981) }\end{array}$ & $\begin{array}{c}\text { Molecular } \\
\text { coancestry } \\
\text { method } \\
\text { (Nomura et al. } \\
\text { 2008) }\end{array}$ & $\begin{array}{c}\text { Moment-based F- } \\
\text { statistics } \\
\text { estimator } \\
\text { (Waples 1989; } \\
\text { Jorde \& Ryman } \\
2007)\end{array}$ & $\begin{array}{c}\text { Unweighted } \\
\text { harmonic mean }\end{array}$ \\
\hline DEU & $29[18-49]$ & $38.3[30-50]$ & $4.7[1.9-8.7]$ & $25.5[17.4-35]$ & 12.8 \\
\hline HAR & $39[25-61]$ & $35.9[29.1-45]$ & infinity & $34[22.6-47.7]$ & 48.2 \\
\hline
\end{tabular}

844

845

846

847

848

849

850

851

852

853 


\section{FIGURE LEGENDS:}

855

856 Figure 1: Location of the two study sites: Pedra de Deu (DEU) in the Medes Islands within 857 the Parc Natural del Montgrí, illes Medes i Baix Ter (Spain) and Grotte Harmelin (HAR)

858 within the Réserve Naturelle de Scandola in Corsica (France). Pictures A and B show

859 populations DEU and HAR, respectively. The same quadrat $(20 \times 20 \mathrm{~cm})$ is used in the two

860 pictures.

861

862 Figure 2: Kinship structure among larvae from each population (DEU and HAR) 863 reconstructed based on their multilocus genotypes using COLONY. L/M: number of larvae per 864 mother; L/F: number of larvae per putative father. Grey and blue squares correspond to one and 865 two larvae, respectively, for the mother-putative father pair considered. * pair of larvae inferred 866 as fullsib with a probability higher than 0.8 .

867 


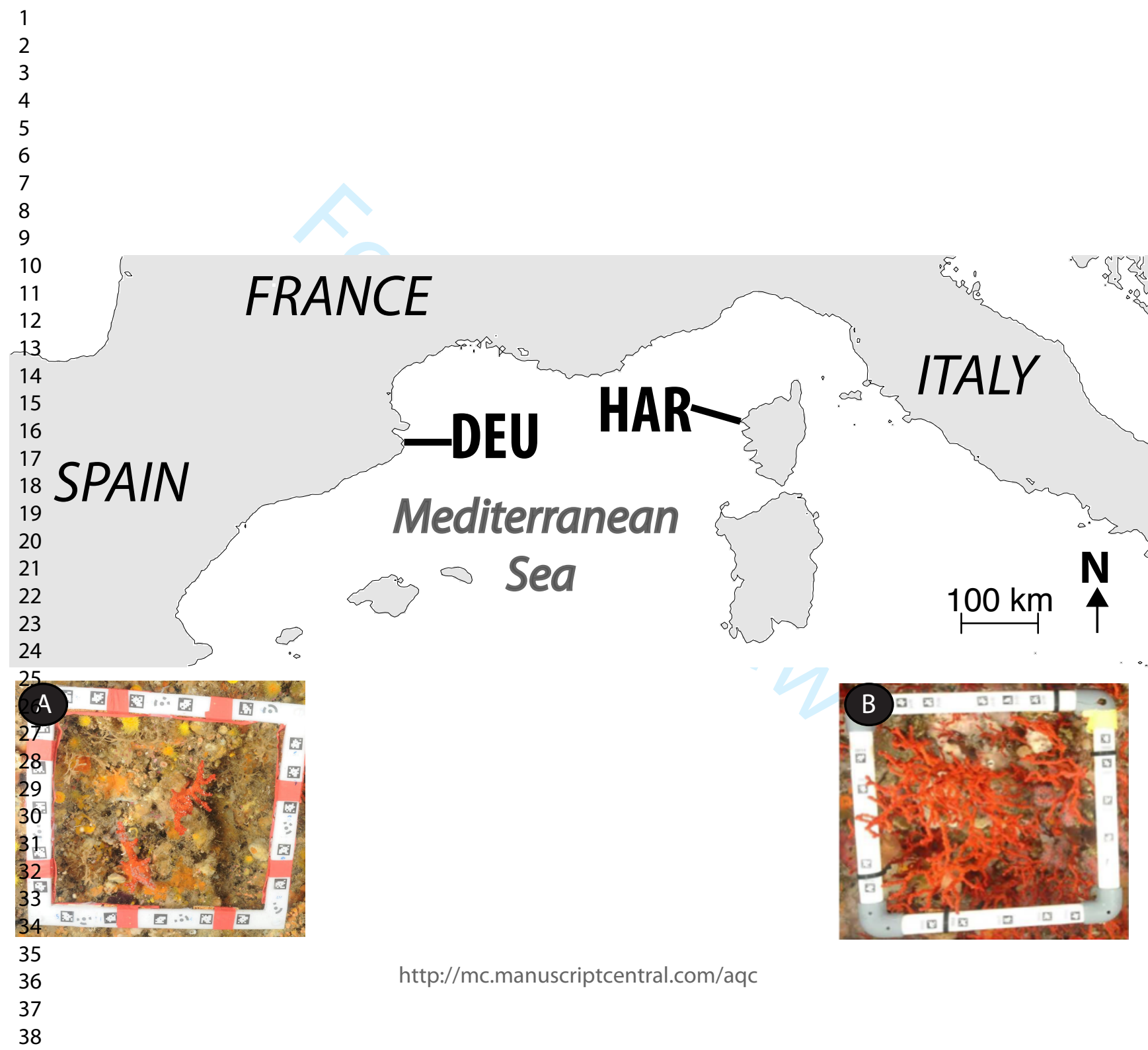



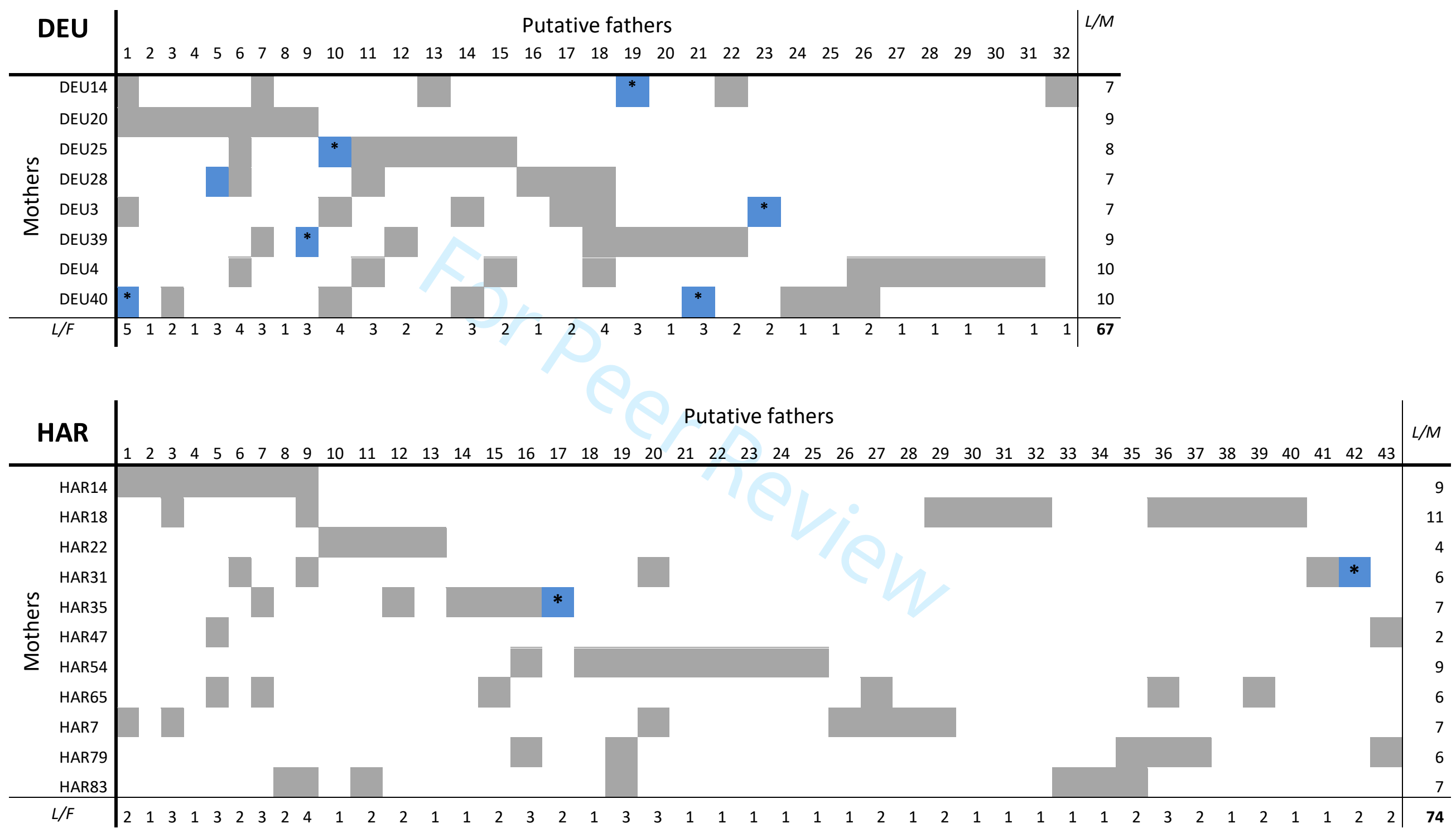
1 Table 1: Characteristics and genetic diversity of each stage class in each site (DEU and HAR). $N$ : number of individuals; $r$ : frequency of null 2 alleles; $H_{o}$ : observed heterozygosity; $H_{e}$ : gene diversity; $A r_{(56}$ : rarefied allelic richness considering a minimum of 56 genes at a locus in a 3 population; $F_{\text {INEST: }}$ estimate of inbreeding coefficient unbiased by null alleles.

4

\begin{tabular}{|c|c|c|c|c|c|c|c|}
\hline & $N$ & $r$ & $H_{0}$ & $H_{e}$ & Ar & $\operatorname{Ar}_{(56)}$ & $F_{\text {INEST }}$ \\
\hline DEU-AD & 30 & 0.12 & 0.52 & \begin{tabular}{|r}
0.72 \\
\end{tabular} & 11.25 & 11.1 & 0.04 \\
\hline DEU-LAR & 67 & 0.12 & 0.49 & 0.69 & 11 & 9.1 & 0.02 \\
\hline HAR-AD & 33 & 0.09 & 0.53 & 0.66 & 10.62 & 10.3 & 0.03 \\
\hline HAR-LAR & 74 & 0.09 & 0.52 & 0.65 & 11.62 & 9 & 0.01 \\
\hline
\end{tabular}


8 Table 2: Mating system characteristics for each site. $t_{m}$ : multilocus outcrossing rate; $t_{s}$ : single

9 outcrossing rate; $t_{m}-t_{s}$ : level of biparental inbreeding; $r_{(p)}$ : correlated paternity. The $95 \%$

10 confidence intervals $(95 \% \mathrm{CI})$ of each parameter was estimated by resampling families 1000

11 times.

12

13

\begin{tabular}{|l|l|l|l|l|}
\cline { 2 - 5 } \multicolumn{1}{c|}{} & \multicolumn{1}{c|}{$\begin{array}{c}\text { Multilocus outcrossing } \\
\text { rate }\left(t_{m}\right) \text { and } 95 \% \mathrm{Cl}\end{array}$} & $\begin{array}{c}\text { Single outcrossing rate } \\
\left(t_{s}\right) \text { and } 95 \% \mathrm{Cl}\end{array}$ & $\begin{array}{c}\text { Biparental inbreeding } \\
\left(t_{m}-t_{s}\right) \text { and } 95 \% \mathrm{Cl}\end{array}$ & $\begin{array}{c}\text { Correlated paternity } r_{(p)} \\
\text { and } 95 \% \mathrm{Cl}\end{array}$ \\
\hline DEU & $0.99[0.95 ; 1.2]$ & $0.78[0.64 ; 0.89]$ & $0.21[0.13 ; 0.45]$ & $0.23[0.09 ; 0,46]$ \\
\hline HAR & $0.94[0.86 ; 1]$ & $0.77[0.67 ; 0.88]$ & $0.17[0.07 ; 0.26]$ & $0.12[-0.03 ; 0.25]$ \\
\hline
\end{tabular}

14

15

16

17

18

19

20

21

22

23

24

25

26

27

28 
29 Table 3: Estimates of relatedness for each stage-class in each population using the $L L$ : Lynch30 Li moment-estimator of relatedness. Observed value corresponds to the difference between 31 adults and larvae in each population. The significance of the differences among the two stage32 classes was tested using on 1000 bootstraps. Significant differences are shown in bold.

\begin{tabular}{|c|c|c|}
\hline & Lynch-Li & Observed Value and $95 \% \mathrm{Cl}$ \\
\hline DEU-AD & $-8.84 * 10^{-2}$ & \multirow{2}{*}{$\begin{array}{c}9 * 10^{-2} \\
{\left[-2.5 * 10^{-2} ; 2.51 * 10^{-2}\right]}\end{array}$} \\
\hline DEU-LAR & $2.31 * 10^{-3}$ & \\
\hline HAR-AD & $5.28 * 10^{-2}$ & \multirow{2}{*}{$\begin{array}{c}2.37 * 10^{-2} \\
{\left[-2.55 * 10^{-2} ; 1.95 * 10^{-2}\right]}\end{array}$} \\
\hline HAR-LAR & $7.65 * 10^{-2}$ & \\
\hline
\end{tabular}

35 
49 Table 4: Effective population size and $95 \%$ confidence interval (between brackets) computed 50 for each site using: i) the sibship assignment method; ii) the standard linkage disequilibrium 51 method; iii) the method based on molecular coancestry; and iv) the moment based F-statistics 52 methods.

53 54 55

\begin{tabular}{|l|c|c|c|c|c|}
\cline { 2 - 6 } & $\begin{array}{c}\text { Sibship } \\
\text { assignment } \\
\text { method } \\
\text { (Wang 2009) }\end{array}$ & $\begin{array}{c}\text { Standard linkage } \\
\text { disequilibrium } \\
\text { method } \\
\text { (Hill 1981) }\end{array}$ & $\begin{array}{c}\text { Molecular } \\
\text { coancestry } \\
\text { method (Nomura } \\
\text { et al. 2008) }\end{array}$ & $\begin{array}{c}\text { Moment-based F- } \\
\text { statistics estimator } \\
\text { (Waples 1989; } \\
\text { Jorde \& Ryman } \\
\text { 2007) }\end{array}$ & $\begin{array}{c}\text { Unweighted } \\
\text { harmonic mean }\end{array}$ \\
\hline DEU & $29[18-49]$ & $38.3[30-50]$ & $4.7[1.9-8.7]$ & $25.5[17.4-35]$ & 12.8 \\
\hline HAR & $39[25-61]$ & $35.9[29.1-45]$ & infinity & $34[22.6-47.7]$ & 48.2 \\
\hline
\end{tabular}
56 57 58 59 60 